\title{
Mammalian gonocyte and spermatogonia differentiation: recent advances and remaining challenges
}

\author{
Gurpreet Manku1,2,3 and Martine Culty ${ }^{1,2,3}$ \\ ${ }^{1}$ The Research Institute of the McGill University Health Centre, Montreal General Hospital, 1650 Cedar Avenue, \\ Montreal, Quebec, Canada H3G 1A4, Departments of ${ }^{2}$ Medicine and ${ }^{3}$ Pharmacology and Therapeutics, McGill \\ University, Montreal, Quebec, Canada
}

Correspondence should be addressed to M Culty; Email: martine.culty@mcgill.ca

\begin{abstract}
The production of spermatozoa relies on a pool of spermatogonial stem cells (SSCs), formed in infancy from the differentiation of their precursor cells, the gonocytes. Throughout adult life, SSCs will either self-renew or differentiate, in order to maintain a stem cell reserve while providing cells to the spermatogenic cycle. By contrast, gonocytes represent a transient and finite phase of development leading to the formation of SSCs or spermatogonia of the first spermatogenic wave. Gonocyte development involves phases of quiescence, cell proliferation, migration, and differentiation. Spermatogonia, on the other hand, remain located at the basement membrane of the seminiferous tubules throughout their successive phases of proliferation and differentiation. Apoptosis is an integral part of both developmental phases, allowing for the removal of defective cells and the maintenance of proper germ-Sertoli cell ratios. While gonocytes and spermatogonia mitosis are regulated by distinct factors, they both undergo differentiation in response to retinoic acid. In contrast to postpubertal spermatogenesis, the early steps of germ cell development have only recently attracted attention, unveiling genes and pathways regulating SSC self-renewal and proliferation. Yet, less is known on the mechanisms regulating differentiation. The processes leading from gonocytes to spermatogonia have been seldom investigated. While the formation of abnormal gonocytes or SSCs could lead to infertility, defective gonocyte differentiation might be at the origin of testicular germ cell tumors. Thus, it is important to better understand the molecular mechanisms regulating these processes. This review summarizes and compares the present knowledge on the mechanisms regulating mammalian gonocyte and spermatogonial differentiation.

Reproduction (2015) 149 R139-R157
\end{abstract}

\section{Introduction}

Spermatogenesis is the process that allows for the continuous formation of spermatozoa throughout adult male life, and for the transfer of genetic material from one generation to the next. It includes two phases separated in humans by a few years of relative testicular quiescence, contrasting with the uninterrupted development of rodent spermatogenesis. The first phase takes place from embryonic ages to infancy. It consists of successive phases of primordial germ cells (PGCs) and gonocytes (also known as pre- or pro-spermatogonia) that can be distinguished by unique features, leading to the formation of the first spermatogonia, including spermatogonial stem cells (SSCs) (Culty 2009). The second phase, starting at prepuberty and extending throughout male adult life, comprises spermatogenic cycles that are initiated by the commitment of spermatogonia to differentiate, progressing through meiosis and spermiogenesis to end with the formation of immature spermatozoa (Hermo et al. 2010). Spermatogenesis occurs within the seminiferous tubules, a group of well organized, long convoluted tubules connecting at both ends to the rete testis, which assure sperm transport to the efferent duct, the initial part of the epididymis (Hermo et al. 2010). The seminiferous tubules are made up of supporting Sertoli cells and germ cells (Bellve et al. 1977), and are surrounded by peritubular myoid cells. The other critical cells of the testis are the interstitial Leydig cells, responsible for androgen production, a key factor in the regulation of male reproductive tract development and spermatogenesis (Christensen 1975, Steinberger \& Steinberger 1975). Although there are differences in the number of days it takes for a spermatogenic cycle to be completed between species, the process itself is similar between humans and rodents, and thus, rodents are commonly used animal models to study this process (Adler 1996).

Male germ cells represent a highly specialized type of cells that undergo considerable morphological, biochemical, and molecular changes throughout their development, starting from the most primitive type, the diploid fetal PGCs, and ending with the formation of haploid flagellated gametes (Setchell et al. 2003). 
The rodent spermatogenic cycle includes three main phases: a mitotic phase that takes place in SSCs, undifferentiated ( $A_{\text {single, }}, A_{\text {pair, }}$ and $\left.A_{\text {aligned }}\right)$, differentiating $\left(A_{1}\right.$ to $A_{4}$, intermediate), and differentiated (type $B$ ) spermatogonia at various phases of maturation, followed by a lengthy meiotic phase including successive types of primary spermatocytes, secondary spermatocytes and the formation of haploid spermatids (round, elongated), which undergo spermiogenesis to become spermatozoa that will further achieve maturation in the epididymis (Hermo et al. 2010). The human cycle is very similar, despite presenting stages spread over much longer periods (days instead of hours) and with the exception of having only three types of spermatogonia, $A_{\text {dark }}, A_{\text {pale, }}$ and $B$. This continuous and dynamic process results in the production, in humans, of millions of mature sperm per gram of testis weight each day (Amman \& Howards 1980). Numerous studies have added to the ever-growing understanding of mechanisms underlying sperm formation. Over the last decade, an increasing number of studies have broadened our knowledge of the genes critical for SSC self-renewal and proliferation. In comparison, few studies have focused on the fetal to perinatal phases of germ cell development at the origin of SSCs.

The germ cell lineage is initiated by the specification of embryonic cells to adopt the germ cell fate under the control of bone morphogenic protein 4 (BMP4) and $\mathrm{BMP} 8 \mathrm{~b}$, starting with the formation of PGC precursors expressing PRDM1 (BLIMP1) and PRDM14, detected around embryonic day (E) 6.25 in the proximal epiblast, which further evolves to alkaline phosphatase and Stella-expressing PGCs at E7.25 (Kurimoto et al. 2008; review in Saitou (2009)). At E7.5, these sexually undifferentiated PGCs start migrating toward the genital ridge, involving the interactions of the membrane receptors KIT (c-Kit/CD117) and CXCR4 with their respective ligands SCF and SDF1, where they will become resident and enclosed by Sertoli cells, forming testicular cords at E12.5dpc in rodents (reviewed in Jan et al. (2012)). During their migration, PGCs undergo genome-wide DNA demethylation, leading to the erasure of parental imprints (Reik et al. 2001, Seki et al. 2005). Sex determination is established at E12.5 in both germ and supporting somatic cells, based in part on the expression of the Sry gene in male somatic cells (Jameson et al. 2012). Once the testicular cords have formed, the germ cells present in the cord are referred to as gonocytes (Zhao \& Garbers 2002, Rouillier-Fabre et al. 2003, Culty 2009, 2013).

Gonocytes are the sole source of a functional reservoir of SSCs necessary to ensure life-long production of sperm (Culty 2009, 2013). Gonocytes encompass a succession of cell types with distinct behaviors that are associated with different fetal and neonatal periods, including a period of fetal mitosis, a phase of quiescence starting around E17.5 in rats and ending at postnatal day 3 (PND3), at which point gonocytes re-enter mitosis and start migrating toward the basement membrane of the seminiferous cords, where they undergo differentiation into SSCs or type A spermatogonia of the first spermatogenic wave (Culty 2009). These events, which occur 1-2 days earlier in mice, are not precisely synchronized, resulting in the co-existence of quiescent and proliferative gonocytes in neonatal testes (Culty 2013). One common characteristic of fetal and postnatal gonocytes is that they are the site of intense DNA remethylation, required for the acquisition of paternal imprints and transposon silencing (Trasler 2009). While platelet-derived growth factor-BB (PDGF-BB) and $17 \beta-$ estradiol were shown to induce neonatal gonocyte proliferation via MAPK activation ( $\mathrm{Li}$ et al. 1997, Basciani et al. 2008, Thuillier et al. 2010), the factors inducing fetal gonocyte proliferation have not been fully identified. The difference between mitotic fetal and neonatal rat gonocytes was clearly illustrated by their different responses to all-trans retinoic acid (RA) in organ culture studies. In E14.5 gonocytes, RA was found to increase fetal gonocyte proliferation, while inducing apoptosis at a greater rate, leading to an overall loss of cells (Livera et al. 2000). However, in the same study, RA was reported to slightly increase PND3 gonocyte numbers and have no effect on apoptosis. Moreover, activin $\mathrm{A}$ and androgen were reported to be negative regulators of fetal gonocyte proliferation, whereas we did not find any effect of testosterone on PND3 gonocyte proliferation in vitro (Merlet et al. 2007, Thuillier et al. 2010, Mendis et al. 2011).

Studies have demonstrated that the timing of events is as critical as their amplitude to adequately regulate gonocyte development. For example, it has been recently shown that the constitutive activation of the Notch pathway in fetal Sertoli cells led to premature changes in the behavior of fetal gonocyte, including premature exit from quiescence, migration, and differentiation, resulting in the loss of germ cells before birth (Garcia \& Hofmann 2013, Garcia et al. 2013). Interestingly, based on morphological and gene expression similarities, it has been suggested that improper gonocyte differentiation could lead to the formation of carcinoma in situ, the precursor pathology to testicular germ cell tumors (TGCTs; Skakkebaek et al. 1987, Sonne et al. 2009). Notably, the incidence of TGCTs has steadily been increasing over the past decades, for reasons that remain unknown (Huyghe et al. 2003). Although the increased exposure to endocrine-disrupting compounds is often blamed (Skakkebaek et al. 2001), the underlying mechanisms through which these tumors are developing are yet to be elucidated. Hence, a better understanding of normal gonocyte development could allow for a better comprehension of the origins of testicular tumors. Therefore, the goal of this review is to survey the available literature on gonocyte differentiation and to compare it with what 
is known of SSC and spermatogonial differentiation in rodents, concluding with some information about these processes in human, primates, and other species. This will allow for a better understanding of the differences between these two critical but often over-looked phases of germ cell development.

\section{Transitional gonocyte differentiation in rodents}

Owing to the multiple changes occurring in the last phase of gonocyte development, it has been proposed to refer to them as 'transitional' gonocytes (Culty 2013). In the remainder of the review, which focuses on this specific phase of gonocyte development, we will refer to these cells as either 'transitional', or simply as 'gonocytes'. Of all of the processes involved in gonocyte development, transitional gonocyte differentiation is the least studied. This is surprising in light of the fact that gonocytes differentiate into SSCs, which are essential for the production of spermatozoa throughout the lifetime of a male. Morphologically, gonocytes and spermatogonia do not look similar. Fetal and neonatal gonocytes are large round cells with prominent nuclei, located at the centre of the seminiferous cords (Clermont \& Perey 1957), whereas spermatogonia are semicircular in shape and are located at the periphery of the seminiferous tubules, with the flattest edge in apposition to the basement membrane. However, despite these differences and presence at different ages, it is during the transitional phase, especially at PND5 and PND6 in rat, when some perfectly round gonocytes still have not yet undergone differentiation but are already located at the basement membrane, that uncertainty can occur regarding the identity of the cell. At such times, morphology and location within the tubule alone are not sufficient to characterize the cells as being still gonocytes and not already transitioned to spermatogonia (Culty 2009). Owing to the lack of synchronization in gonocyte development, the absence of a marker exclusively expressed in gonocytes, and the several day-long transition time frame in rodents (weeks to months in humans), it is impossible to clearly determine a day at which gonocyte differentiation has ended and spermatogonial self-renewal has started, making the study of gonocyte differentiation a challenging topic.

Yet, over the last years, several genes have been characterized as indicators of gonocyte differentiation, simplifying the study of factors and pathways regulating this process. One of these markers is stimulated by RA8 (STRA8), first identified as a target gene of RA in P19 mouse embryonal carcinoma cells, and later, in F9 mouse embryonal teratocarcinoma cells, undifferentiated spermatogonia, and premeiotic male germ cells (Bouillet et al. 1995, Oulad-Abdelghani et al. 1996, Giuili et al. 2002, Zhou et al. 2008a). Since then, the role of STRA8 as an essential initiator of meiosis in male and female germ cells has been clearly demonstrated in Stra8 knockout mice that were infertile, due to disrupted meiosis and premature chromosome condensation (Baltus et al. 2006, Anderson et al. 2008, Mark et al. 2008). Although the exact mechanism through which STRA8 induces meiosis is not well understood, the protein has been shown to shuttle between the cytoplasm and the nucleus in different types of germ cells, and to display transcriptional activity in cell lines when it is expressed in the nucleus (Tedesco et al. 2009). Several groups, including ours, have used STRA8, alongside KIT (another marker of differentiating spermatogonia), as a marker for differentiating gonocytes (Wang \& Culty 2007, Zhou et al. 2008b). As mentioned before (Culty 2009), transcript and protein expression changes in these markers of differentiation are convenient surrogates for determining whether a gonocyte has initiated differentiation, but these changes reflect only some aspects of the alterations in the complexes taking place during the transition from gonocyte to spermatogonia. Indeed, it is likely that RA-treated gonocytes do not recapitulate the entire differentiation process, especially considering that differentiation to spermatogonia is achieved only when the cells establish close contact with the basement membrane. Nonetheless, this is a convenient tool that allows dissecting some of the signaling pathways and molecular changes occurring in response to RA, which remains, as far as we know, the only demonstrated inducer of differentiation in gonocytes.

Our work has shown that PND3 rat gonocyte differentiation is induced in vitro by RA (Wang \& Culty 2007). Although in vivo and freshly isolated gonocytes express little STRA8 mRNA and protein at PND3, the addition of RA, an active metabolite of vitamin A (Collins \& Mao 1999), to isolated gonocytes induces a strong and consistent increase in Stra8 mRNA (Wang \& Culty 2007). This is followed by an increase in protein expression, mainly located in the cytoplasm, suggesting that STRA8 is maintained as an inactive form in gonocytes (Sarkar and Culty, unpublished observations). Similar to our findings in rats, studies have shown that mouse PND2 gonocytes also differentiate in response to RA, as indicated by increased Stra8 mRNA levels (Zhou et al. 2008b). The importance of vitamin A and $\mathrm{RA}$ in spermatogenesis has been known for many years due to the use of a vitamin A-deficient mouse model (VAD mice). Studies have demonstrated that in VAD adult mice, all differentiated germ cells are lost from the seminiferous tubules and the only cells remaining are undifferentiated type A spermatogonia and Sertoli cells (Mitranond et al. 1979, Van Pelt \& de Rooij 1990). However, once these rats are administered vitamin A, normal spermatogenesis can be rescued (Morales \& Griswold 1987, Griswold et al. 1989). At first, studies demonstrated that normal spermatogenesis could only resume if vitamin A (retinol) was given to the deficient mice and that the same results were not observed upon 
RA administration (Ahluwalia \& Bieri 1971, Huang et al. 1983). However, later studies demonstrated that RA could also stimulate normal spermatogenesis in these deficient mice, but at a much higher dose than retinol, probably due to differences in the levels of binding proteins for each of these retinoids in Sertoli cells (Van Pelt \& de Rooij 1991).

In order to induce differentiation, retinol is delivered to the gonocyte via the retinol-binding protein (RBP) from Sertoli cells or the serum (Hogarth \& Griswold 2010, 2013). Retinol is then internalized after binding to a membrane receptor, STRA6 (Kawaguchi et al. 2007, Hogarth \& Griswold 2010). Inside the cell, retinol then undergoes the two-step oxidation process in order to become RA (Theodosiou et al. 2010). It is also possible that RA is directly transported to the gonocytes from the serum (via the vasculature) or Sertoli cells (Hogarth \& Griswold 2010, 2013). Although spermatids and testicular and epididymal sperm are known to be able to store retinoids, Sertoli cells are the main site of RA synthesis in the testis, which is then passed onto the germ cells (Livera et al. 2002). Interestingly, RA was shown to be present in patches along the seminiferous cords of neonatal mice, while CYP26B1, the enzyme degrading RA, was expressed in a non-uniform manner in germ cells along the tubules (Snyder et al. 2010). Although these studies were carried out using PND2 mice, this developmental period is similar to that of PND3-PND4 in rats. Thus, it is likely that these factors also play a role in the lack of synchronization of gonocyte progression to spermatogonia, within the few days encompassing this process. It is not known whether, in vivo, RA induces differentiation by acting directly on the germ cells or if it is an indirect process involving Sertoli cells, as both cell types express RA receptors (RARs) and retinoid $X$ receptors (RXRs) at varying levels (Akmal et al. 1997, de Rooij \& Russell 2000). It has been shown that at PND3, gonocytes express all isoforms of RARs and RXRs, mainly high levels of RARA and RXRA, whereas Sertoli cells express mainly RXRG (Boulogne et al. 1999). Other groups have reported that PND3 gonocytes do not express RARA and that, at PND3, this receptor isoform is expressed solely in Sertoli cells, while gonocytes express RARG (Vernet et al. 2006a,b). However, differences in expression levels could also be attributed to the different affinities of the antibodies used for their respective targets. In our own studies, we have found that rat PND3 gonocytes express high levels of both Rara and Rarg (Manku et al. 2014).

Although both mice and rat gonocytes are stimulated by RA to undergo differentiation, the signaling pathways in mouse gonocytes have not been identified yet. In rats, we have found that the PDGF receptor (PDGFR) signaling pathway probably plays an important role in gonocyte differentiation (Wang \& Culty 2007, Manku et al. 2014). It is already known that PDGFR expression begins to steadily increase at $18 \mathrm{dpc}$ and continues to increase until PND5, at which time this expression begins to decline (Loveland et al. 1993). We have found that rat spermatogonia at PND7 have significantly lower PDGFR expression compared with PND3 gonocytes, indicating a possible preferential role of these receptors in gonocyte development ( $\mathrm{Li}$ et al. 1997). In studies on isolated PND3 rat gonocytes, we found that RA induced the formation of variant forms of PDGFR $\alpha$ ( $v$-PDGFRA) and PDGFR $\beta$ (V1-PDGFRB), concomitant with the increases in Stra8 expression (Wang \& Culty 2007, Manku et al. 2014). We have previously shown that the variant V1-PDGFRB form has retained its tyrosine kinase domain, while lacking the ligand-binding domain, and thus, it is ligand independent (Wang \& Culty 2007). We have recently found that the variant $v$-PDGFRA includes exons 12-23, corresponding to the C-terminal portion of the protein, but it has yet to be fully characterized (Manku et al. 2014). Moreover, the inhibition of the tyrosine kinase activity of PDGFR using tyrphostin compounds alongside RA treatment led to a significant reduction in the RA-induced Stra8 mRNA expression, indicating that PDGFR activation is required for RA-dependent induction of gonocyte differentiation. The analysis of downstream pathways commonly activated upon PDGFR activation showed that activation of the SRC family of kinases and the JAK2/STAT5 signaling pathways were both involved in RA-induced gonocyte differentiation (Manku et al. 2014). Considering that STAT5 is a possible downstream target of SRC (Drayer et al. 2005), it will be important to determine whether it is activated via JAK2, SRC, or another pathway in gonocytes. The presence of a variant PDGFRA form in gonocytes is interesting in view of the existence of a similar variant transcript identified in seminomas, the most common type of TGCTs (Palumbo et al. 2002), and because of the possible relationship between improper gonocyte development and TGCT formation (Rajpert-De Meyts \& Hoei-Hansen 2007).

Another system that plays a role in gonocyte differentiation is the ubiquitin-proteasome system (UPS), as revealed by studies where we have demonstrated that inhibiting proteasome activation with the specific inhibitors lactacystin and bortezomib significantly decreased the RA-driven induction of Stra8 expression in rat gonocytes (Manku et al. 2012). In this study, we also identified several UPS proteins preferentially expressed in gonocytes, such as the E3 ligase RNF149, that might have a role in gonocyte development. Several UPS proteins have been implicated in the regulation of spermatogenesis, including the E3 ligase Huwe1 (Liu et al. 2007). The involvement of the ubiquitin-proteasome system in gonocyte differentiation is not surprising considering the large amount of remodeling taking place during gonocyte development, but further studies are needed to identify the functional enzyme-substrate partners and their respective roles in gonocyte development. 
Several hormones have been examined for their potential role in gonocyte differentiation. For example, Zhou \& Hutson (1995) have shown that human chorionic gonadotropin (hCG) does not have any effect on gonocyte differentiation in neonatal mouse testis organ cultures, refuting the hypothesis that this process was under the control of the hypothalamic-pituitarygonadal axis. By contrast, this study showed that the addition of Mullerian inhibiting substance (MIS; also known as anti-Mullerian hormone $(\mathrm{AMH})$ ), a protein produced by fetal to juvenile Sertoli cells, significantly increased the number of gonocytes undergoing differentiation into type A spermatogonia, suggesting a role of this protein in the regulation of gonocyte fate (Zhou \& Hutson 1995).

More recent studies have demonstrated the importance of NOTCH signaling in the timing of gonocyte differentiation. The NOTCH pathway has been shown to be involved in a multitude of processes, including cell proliferation, cell differentiation, and cell-cell communication. Furthermore, various components of the $\mathrm{NOTCH}$ pathway are expressed in neonatal and adult testes in both rodents and humans (Dirami et al. 2001). Recent studies have demonstrated that NOTCH signaling in fetal Sertoli cells is critical for the maintenance of fetal gonocytes in a quiescent state and to exert a brake on the ability of fetal gonocytes to undergo differentiation (Garcia \& Hofmann 2013). Using a Sertoli cell-specific NOTCH gain-of-function mouse model (Amh-cre;RosaNICD/+ ${ }^{+}$, in which the Notch intracellular domain NICD is constitutively activated, leading to the conversion of the transcriptional repressor RBPJ (recombining binding protein suppressor of hairless) to an activator, this study demonstrated that the constitutive activation of $\mathrm{NOTCH}$ signaling in Sertoli cells at E13.5 induced gonocyte exit from quiescence, and premature migration and differentiation. At the molecular level, there was a decrease in Sertoli-specific factors that generally help maintain germ cells in an undifferentiated state (i.e. glial-cell-derived neurotropic factor (GDNF)) and, in POU5F1/OCT4, a transcription factor used as a marker of undifferentiated spermatogonia. Concurrent with these decreases, there was increased expression of markers of differentiating spermatogonia, such as KIT and spermatogenesis- and oogenesis-specific bHLH transcription factor 2 (SOHLH2), indicating that these gonocytes had acquired properties of differentiating spermatogonia (Garcia et al. 2013). Given their findings, the authors concluded that $\mathrm{NOTCH}$ signaling in Sertoli cells is important for germ cell development and that, when over-activated, $\mathrm{NOTCH}$ signaling is able to inhibit quiescence and push germ cell toward differentiation and meiosis (Garcia et al. 2013). Interestingly, adult mice in which a Stra8-icre transgene was used to induce NOTCH1 gain of function in germ cells also do not have proper spermatogenesis as witnessed by decreased sperm count, decreased testis weight, and abnormal seminiferous tubules
(Huang et al. 2013). These defects were presumably due to the failed differentiation of SSCs presenting abnormal activation of $\mathrm{NOTCH} 1$, further highlighting the importance of having proper levels of NOTCH1 activation not only in Sertoli cells but also in germ cells.

Interestingly, microRNAs (miRNAs), short untranslated RNA molecules of $\sim 22$ nucleotides that regulate the expression of specific mRNA targets, have also been shown to be involved in gonocyte differentiation. Although studies on testicular miRNAs are limited, it is known that there are miRNAs preferentially or specifically expressed within the testis (Mclver et al. 2012). Using miRNA microarray analysis of isolated gonocytes and spermatogonia from mice, the authors identified miRNAs that were differentially expressed between gonocytes and spermatogonia. In particular, miR-126, miR-743a, and miR-463 were higher in spermatogonia, whereas miR-293, miR-291a-5p, miR-290-5p, and miR-294 were lower in spermatogonia. One of the miRNA clusters downregulated during the transition from gonocytes to spermatogonia, including miR-293, miR-294, miR-291, and miR-290-5p, has been previously shown to play a role in the maintenance of embryonic stem cell (ESC) pluripotency. Functional analysis of these miRNAs indicated a variety of different pathways to which these miRNAs belonged. Of those pathways, it was the PTEN and $\mathrm{Wnt} / \beta$-catenin signaling pathways that were associated with the majority of miRNAs, pinpointing to the cell cycle regulator cyclin D1 as a common target of both pathways. Given the known role of Cyclin D1 in promoting cell progression to $S$ phase, the authors proposed that the observed miRNA changes between gonocyte and spermatogonia might be related to their role in gonocyte differentiation (Mclver et al. 2012). However, exactly what role these signaling pathways are playing in gonocyte differentiation remains yet to be determined.

Finally, what determines which gonocytes will undergo differentiation, including SSCs or first-wave fates, and which ones are destined for apoptosis are not known. Using isolated rat gonocytes from PND0-PND4, phase-contrast microscopy, Annexin V staining, and transplantation studies, Orwig et al. (2002) have determined that gonocytes with pseudopods were probably destined to undergo migration and differentiation, whereas gonocytes without pseudopods were destined to undergo apoptosis and be eliminated. Thus, it might be possible to distinguish functional subsets of gonocytes according to their in vitro morphology. Different subsets of isolated neonatal rat gonocytes can also be distinguished according to their size, including a group of very large cells ( $>12 \mu \mathrm{m}$ diameter) and a group of medium size (10-12 $\mu \mathrm{m}$ diameter), both populations being much larger than the somatic cells $(5-8 \mu \mathrm{m}$ diameter) isolated from the same testes (Culty, unpublished data). Moreover, we have observed that mitotic gonocytes present daughter cells with different 
immunoreactions for a number of proteins, suggesting that gonocyte division is asymmetrical (Culty, unpublished data). Similarly, studies have shown that there is asymmetrical division in SSCs as well (Luo et al. 2009). Further studies will be required to determine whether these differences correspond to cells with distinct fates and/or functions within the transitional gonocyte population.

In summary, various signaling pathways, such as those involving TGF $\beta$ superfamily ligands, RA, variant forms of PDGFRs, WNTs, and PTEN, have emerged as potential regulators of transitional gonocyte differentiation. However, more work is required to determine the target molecules of these pathways, and how these different pathways communicate with each other in order to fine tune gonocyte differentiation.

\section{Spermatogonia and SSC differentiation}

Although more commonly studied than gonocytes, most work carried out on SSCs have focused on the regulation of their self-renewal potential, a process required for maintaining an adequate pool of stem cells. One major challenge in studying the regulation of SSC differentiation has been the lack of means to isolate this specific subpopulation from other undifferentiated spermatogonia. A protein that has been instrumental over the last decade for the characterization of genes preferentially or highly expressed in SSCs is THY1 (CD90), a glycoprotein expressed at the surface of undifferentiated spermatogonia, including SSCs (Ryu et al. 2004). Indeed, Thy 1 immunosorting has allowed for the preparation of spermatogonial populations enriched in SSCs. Yet, the gold standard for identifying true SSCs remains the functional transplantation assay carried out in germcell-depleted mice, which allows assessing whether transplanted cells can re-initiate spermatogenesis. This approach has been used to determine the impact of chemical or physical insults, such as chemotherapy and radiotherapy cancer treatments, as well as the role of genes following their silencing in germ cells (Brinster \& Avarbock 1994, Brinster \& Zimmermann 1994, McLean et al. 2003). However, it is a delicate and time-consuming method, impractical for the performance of large-scale assays. Moreover, transplantation studies provide only indirect information regarding the stemness nature of cells, as the presence of SSCs is deduced from the numbers of colonies formed over a period of 2-3 months in recipient testes. Thus, there is still limited information on the mechanisms behind SSC differentiation.

The identification of genes highly expressed in SSCs has also been critical in the study of SSC differentiation. Thus, genes involved in SSC self-renewal will be briefly mentioned below, because of their use in isolating SSCenriched spermatogonia and characterizing SSCs, and because some of their gene products were shown to actively repress spermatogonial differentiation. Among the most frequently cited SSC markers are the GDNF receptors GFR $\alpha 1$ and RET, alongside OCT4 (POU5F1/OCT3/4), PLZF (promyelocytic leukemia zinc finger; ZBTB16/ZFP145), LIN28A, BCL6B, NGN3, ID4, CDH1, UTF1, and SALL4 (reviewed by Nagano \& Yeh (2013) and Song \& Wilkinson (2014)). In contrast to the regulation of SSC maintenance, there are fewer proteins that have been implicated in the process of spermatogonial differentiation, such as the RA receptor RAR $\gamma$, and the RA-induced proteins STRA 8 and KIT, SOHLH1 and SOHLH2, shown to be upregulated during SSC differentiation (Oatley \& Brinster 2012). Moreover, the exact mechanisms through which these proteins act and their respective roles during differentiation remain yet to be determined.

It is known that RA is an upstream regulator of KIT and STRA8 expression during the transition from undifferentiated to differentiated spermatogonia, making them convenient markers in the distinction of these two germ cell phases (Schrans-Stassen et al. 1999, Zhou et al. 2008a,b). Similarly, we have shown that RA treatment upregulates Stra8 and Kit mRNA expression in neonatal rat gonocytes (Wang \& Culty 2007). As RA also stimulates the differentiation of PND5-PND6 mouse spermatogonia, it is presumed that it is inducing SSC differentiation. However, the definitive demonstration of this fact would require the ability to distinguish SSCs from first-wave spermatogonia during the first postnatal week in rodents, which, as explained above, still remains a challenge, due to the lack of a marker restricted to SSCs. Thus far, it is not clear whether predetermined subsets of gonocytes are destined to either the first wave or SSCs, or if specific combinations of factors, probably including RA, combined with differential intratubular locations, will dictate which gonocytes become SSCs or enter the first-wave process. Similarly, there is no information on whether the progression of the first-wave germ cells from type A to B spermatogonia involves the same factors as in subsequent postpubertal spermatogenic waves. However, several studies have described conditions, either knockout models or toxicant exposures, in which the germ cells of the first wave were spared and progressed through part or all of the first spermatogenic cycle, whereas subsequent cycles were impaired, leading to the inability to further generate differentiated germ cells. Rather than identifying mechanisms involved in the differentiation of first-wave spermatogonia, these studies provided information on molecules that are not required for this process, but are involved either in a later step of spermatogenesis or in SSC formation. However, to our knowledge, there is no report of an experimental or pathological condition in which the formation of the first-wave spermatogonia would be disrupted, but not that of SSCs. Despite these uncertainties, a number of genes and mechanisms have been proposed to induce SSC differentiation. This section will review some of the well-established and novel 
inducers of spermatogonial differentiation during the first postnatal week in rodents, a period in which SSCs represent the highest proportion of germ cells, as distinct from later ages.

SSCs arise from RA-induced gonocyte differentiation, forming a stem cell reservoir located in a niche constituting somatic cells, principally Sertoli cells and peritubular myoid cells, which provides nutrients and regulatory factors to the SSCs (reviewed in Oatley \& Brinster (2012)). At the same time, a small subset of gonocytes is believed to bypass the SSC phase to directly differentiate into the spermatogonia of the first spermatogenic wave (Yoshida et al. 2006). The first wave of spermatogenesis is less efficient and encompasses larger levels of apoptosis than subsequent steady-state cycles of spermatogenesis, and it is likely that the spermatozoa resulting from this first round may not be fertile (Kluin et al. 1982, Mori et al. 1997, Yoshida et al. 2006). Based on lineage analysis studies in association with transplantation assays, and using the basic helix-loop-helix transcription factor neurogenin 3 (Ngn3/Neurog3) as a marker of undifferentiated spermatogonia, including SSCs, and Kit as a marker of differentiating spermatogonia, Yoshida et al.'s study suggested that the first wave arises from the direct differentiation of $\mathrm{NGN} 3^{-}$gonocytes into $\mathrm{NGN} 3^{-}$spermatogonia, distinguishable from the pool of $\mathrm{NGN} 3^{+}$SSCs at the origin of steady-state spermatogenesis. In a subsequent study, these authors followed $\mathrm{NGN}^{+}{ }^{+}$spermatogonia fate using pulse-chase experiments in tamoxifen-inducible Ngn3/CreER;CAGCAT-Z transgenic mice, generated by crossing tamoxifeninducible Ngn3-CreER mice with CAG-CAT-Z mice (with the Cat gene floxed by loxP-preventing lacZ expression) (Nakagawa et al. 2007). This strategy allowed the authors to perform pulse-chase labeling of NGN3-expressing cells for different periods of time, and to follow their fate in transplantation and regeneration studies using lac $Z$ as a reporter gene for up to 1 year after labeling. These studies unveiled the co-existence of two distinct populations within the $\mathrm{Ngn}^{+}$undifferentiated $\left(\mathrm{A}_{\text {single, }}\right.$ $A_{\text {pair }}$ and $A_{\text {aligned }}$ ) spermatogonia, one constituting true SSCs and the other corresponding to a transit amplifying population of cells ('potential stem cells') that retained the ability to self-renew in specific conditions, where the replenishment of the SSC pool was required. However, a later study using additional markers proposed that true SSCs are included among a group of $\mathrm{Ngn}^{-}$ undifferentiated spermatogonia, and that $\mathrm{NGN}^{+}$ spermatogonia represent transit amplifying progenitor spermatogonia issued from the SSCs (Suzuki et al. 2009). This difference illustrates a recurring problem linked to the difficulty of establishing definitive SSC identity (Hermann et al. 2011). Indeed, over the years, many genes labeled as SSC markers were subsequently found to be expressed in other types of undifferentiated spermatogonia apparently committed to differentiation. This incapacity of unequivocally delineating SSCs among undifferentiated spermatogonia is consistent with the hypothesis that spermatogonia-type $A_{\text {pair }}$ or $A_{\text {aligned }}$ might be able in specific conditions to revert to SSCs (Nakagawa et al. 2007, 2010).

While the studies mentioned above analyzed the expression profiles of NGN3 in spermatogonial populations, others examined the role of NGN3 in spermatogonial differentiation. NGN3 was proposed to drive the differentiation of mouse SSCs and progenitor spermatogonia, as a downstream effector of STAT3induced differentiation (Kaucher et al. 2012). Using $\mathrm{THY}_{1}{ }^{+}$undifferentiated spermatogonia and transplantation assays, these authors showed that the transient inhibition of STAT3 or addition of GDNF both led to decreased NGN3 expression and increased self-renewal potential of Thy $1^{+}$cells. While STAT3 was shown to regulate Ngn3 transcription, Ngn3-deficient $\mathrm{THY}^{+}{ }^{+}$ cells failed to differentiate in transplantation assays. These data concurred with earlier transplantation studies reporting that, upon decreased STAT3 activity, cells could not differentiate beyond the undifferentiated spermatogonia stage in recipient testes (Oatley et al. 2010). Taken together, these studies demonstrated the involvement of STAT3 and NGN3 in the differentiation of SSCs and progenitor spermatogonia. This is different from the role of STAT3 in Drosophila, where it is necessary for SSC self-renewal (Sheng et al. 2009). It is noteworthy that our studies in neonatal gonocytes showed that the RA induction of STRA8 expression also requires an active Stat, in this case, the JAK2/STAT5 pathway (Manku et al. 2014).

During SSC differentiation, RA downregulates ZBTB16/PLZF, which in turn probably leads to the increased expression of KIT in differentiating spermatogonia (Suzuki et al. 2012). Alongside increased KIT expression, RA-induced spermatogonia differentiation also results in increased expression of SOHLH1 (Suzuki et al. 2012), which in turn functions to increase KIT expression as well (Barrios et al. 2012). The role of RA in spermatogonial differentiation was further clarified using Rbp4 null mice, in order to prevent the formation of RA from endogenous retinol pools (Ghyselinck et al. 2006). RA and retinol were reported to induce the in vitro differentiation of spermatogonia, using an organotypic culture system of fresh and frozen PND6 and PND7 mouse testes (Travers et al. 2013). Spermatogonia and primary spermatocytes were visualized using Tra98 immunostaining, which detects germ cell nuclear antigen (GCNA), while undifferentiated and differentiated spermatogonia were identified using $\mathrm{Plzf}^{+}$ and $\mathrm{Kit}^{+}$immunostaining respectively. The authors concluded that in vitro SSC differentiation and subsequent spermatogenesis were feasible even using frozen testes, thus representing an attractive approach that could potentially be used in the future to restore fertility in patients. Barrios et al. have shown that PND4 isolated $\mathrm{NGN}^{+}{ }^{+}, \mathrm{KIT}^{-}$mouse germ cells express high 
levels of NANOS2, a RNA-binding protein involved in SSC self-renewal and in the suppression of spermatogonial differentiation (Suzuki \& Saga 2008, Suzuki et al. 2009, Sada et al. 2012), in response to FGF9, a growth factor produced by Sertoli cells (Barrios et al. 2010). By contrast, the addition of RA reduced NANOS2 expression and concomitantly induced KIT and STRA8 expression in these cells (Barrios et al. 2010). Moreover, in PND7 mice, PLZF, a transcription factor required for SSC maintenance (Buaas et al. 2004), was shown to act as a repressor on the Kit promoter, preventing KIT expression, whereas isolated Thy $1^{+}$spermatogonia from $\mathrm{Plzf}^{-1-}$ mice showed more than a doubling in their KIT expression (Filipponi et al. 2007). Using cell line models and whole-mouse testes, Zhang et al. (2013a) reported that long and short transcripts of Kit are expressed in spermatogonia, the long transcript being mainly expressed in the cytoplasm and cell membrane, while the short transcript was found in nuclei as well as the cytoplasm and cell membrane. They also reported that the long transcript of Kit was not expressed in SSCs, in line with other studies (Payne 2013). This group concluded that there are extensive transcriptional and translational changes in KIT expression before and after SSCs differentiation (Zhang et al. 2013a).

The same authors reported that RA decreased the expression of BMP4 in PND5 mouse testes, but not at PND10 where it was increased by $0.7 \mu \mathrm{M}$ RA, while having no effect on BMP4 expression at PND60. These data suggest that RA exerts different effects on BMP4 in function of age. While the suppressing effect of RA on BMP4 expression at PND5 is surprising, the increase observed at PND10 agrees with earlier studies. Indeed, BMP4 was found to decrease the stem cell maintenance of adult mouse SSCs (Nagano et al. 2003), as well as to induce SSC differentiation by affecting cell adhesion pathways and cytoskeletal proteins in the rat cell line GC-6spg, used as an SSC model (Carlomagno et al. 2010). Moreover, it has been shown that when mouse SSCs undergo differentiation in the presence of BMP4, there is downregulation of PLZF, a pluripotency marker involved in SSC self-renewal, and upregulation of the differentiation marker KIT. During this process, SMAD1/ $5 / 8$ proteins, common downstream components of BMP signaling cascades, are activated. BMP4 was also shown to exert its effect via upregulation of SOHLH2 (Hao et al. 2008), a transcription factor known to promote the differentiation of both SSCs and the cells these SSCs become in knockdown studies (Suzuki et al. 2012). Overall, these studies showed that RA increases BMP4 expression in SSCs, which in turn promotes SSC differentiation to progenitor cells by increasing SOHLH2 and KIT expression, while repressing the selfrenewing potential of SSCs by decreasing PLZF expression. The importance of SOHLH1 and SOHLH2 in spermatogonial differentiation was highlighted in studies showing that $\mathrm{SOHLH} 1 / \mathrm{SOHLH} 2 \mathrm{KO}$ mice had functional spermatogonial proliferation but improper differentiation. It was also determined that SOHLH proteins were able to regulate Gfra1, Sox3, and Kit gene expression. Overall, this study found that SOHLH1 and $\mathrm{SOHLH} 2$ were able to induce genes necessary for spermatogonial differentiation, while at the same time suppressing genes involved in stem cell maintenance (Suzuki et al. 2012).

Regarding the receptors involved in these processes, Gely-Pernot et al. (2012) have shown that RARG (RAR $\gamma$ ) is expressed in $A_{\text {aligned }}$ spermatogonia and during the $A_{\text {aligned }}$ to $A_{1}$ transition, but not in $A_{s}$ or $A_{p}$ spermatogonia. RARG ablation in adult mice prevented the RA-induced transition from $A_{\text {aligned }}$ to $A_{1}$ spermatogonia and led to testicular tubules missing germ cell layers. By contrast, in prepubertal mice, the absence of RARG could be compensated by RARA, as shown by the occurrence of a normal first spermatogenic wave, as well as the worsening of the phenotype in mutant mice with Rara/ $g^{-/-}$spermatogonia (Gely-Pernot et al. 2012). Contrary to mice made VAD at birth, in which only Sertoli cells and undifferentiated GFRA1 and ZBTB16/PLZF-positive spermatogonia could be found, the testes from $\mathrm{Rarg}^{-/-}$mice contained spermatogonia expressing KIT and STRA8, as well as GFRA1 and ZBTB16/PLZF, demonstrating more progression in germ cell differentiation. Similarly, the simultaneous inactivation of RARA and RARG in PND3 spermatogonia was not sufficient to totally prevent the formation of germ cells beyond the undifferentiated stage in all tubules. These data suggest that RA-dependent pathways other than those of RARA and RARG might play a role in prepubertal spermatogonial differentiation.

As in gonocytes, miRNA species have emerged as important regulators of mouse SSC differentiation. However, the two developmental phases appear to involve different families of miRNAs. Previous studies had shown that miR-34c and miR-21 are highly expressed in SSC-enriched Thy $1^{+}$mouse spermatogonia, and showed a role of miR-21 in SSC self-renewal potential, but did not study the function of miR-34 in these cells (Niu et al. 2011). Other studies on ovarian primary epithelial and cancer cells had reported that miR-34 expression decreased cell proliferation upon p53-dependent activation (Corney et al. 2007). These data suggested that miR-34 might have an opposite role to miR-21 by promoting differentiation rather than self-renewal. Indeed, the over-expression of miR-34C in mouse PND6 undifferentiated spermatogonia was found to decrease the expression of NANOS2, leading to the upregulation of NANOS3 and STRA8, markers of spermatogonial differentiation, and premeiosis transition, and that of the meiotic marker SCP3 (Yu et al. 2014). These results suggest that spermatogonial differentiation requires not only the induction of differentiation factors, but also the removal of functional brakes such as NANOS2, probably responsible for preventing premature differentiation. 
The roles of miRNAs in spermatogonial differentiation was further investigated by the team of Dr M Griswold, who showed that the expression of miR-17-92 (Mirc1) and miR-106b-25 (Mirc3) paralog clusters was significantly decreased during the RA-induced differentiation of PND7 $\mathrm{THY}^{+}{ }^{+}$-enriched undifferentiated mouse spermatogonia (Tong et al. 2012). Among the Mirc1 cluster, expression of miR-18a, miR-20a, and miR-92 was mainly observed at PND3, while miR-17 was the highest at PND3 and progressively decreased with age. RA-induced decreases in Mirc1 and Mirc3 in THY $1^{+}$enriched spermatogonia led to increased expression of BCl2/11 (Bim), Kit, and Stat3, important factors in spermatogonial differentiation (Tong et al. 2012). Mirc1 $\mathrm{KO}$ mice had lower epididymal sperm but increased Mirc3 cluster, suggesting interactions between the two clusters. These studies positioned Mirc1 and Mirc3 clusters as negative regulators of undifferentiated spermatogonia. Another miRNA shown to regulate spermatogonial differentiation is miR-146, which was also downregulated in RA-treated undifferentiated spermatogonia (Huszar \& Payne 2013). Alongside this decrease, there was a significant decrease in ZBTB16/ $P L Z F$ expression and increase in Kit expression. Moreover, the over-expression of miR-146 led to decreased expression of Stra8, Kit, and Sohlh2, genes normally associated with spermatogonial differentiation (Huszar \& Payne 2013).

Altogether, these studies demonstrated the participation of several miRNA species as either positive or negative regulators of undifferentiated spermatogonia differentiation. Considering that only a fraction of SSCs commit to differentiation at any given time, it would be interesting to examine whether the temporal and spatial fine tuning of SSC differentiation involves the expression of different sets of miRNAs at different locations and times within the seminiferous tubules.

Another potential regulator of SSC differentiation is activin A, encoded by the gene Inhba, for which contrasting studies are available. Nagano et al. (2003) have shown that activin A decreased stem cell maintenance in SSCs from PND5-PND8 mice co-cultured with TM4 or SF7 Sertoli cell lines, and the ability of these cells to form colonies in transplantation assays, similar to BMP4. As activin A has been previously shown to induce the proliferation of spermatogonia in vitro (Mather et al. 1990), the authors proposed that activin A may decrease the SSC pool by increasing their recruitment to the subset of cells committed to differentiation and induced to mitosis by activin A (Nagano et al. 2003). However, another group using PND0-PND7 Inhba knockin mice (Inhba $\left.{ }^{\mathrm{BK} / \mathrm{BK}}\right)$ in which the mature coding subunit sequence of Inhba had been replaced by the lower affinity Inhbb domain sequence proposed that a reduction of bioactive activin A levels led to the premature increase in markers of differentiated germ cells such as KIT, and suggested that activin A is critical for the proper coordination of germ cell maturation, as well as for Sertoli cell proliferation (Mithraprabhu et al. 2010). Interestingly, differentiating neonatal gonocytes were shown to be negative for activin A protein expression, with Inhba mRNA presenting a sharp decrease between PND3 and PND6 in mice, and instead to express the activin inhibitor follistatin (Meehan et al. 2000, Mithraprabhu et al. 2010). Simultaneous to the decrease in activin A during the first postnatal week, there was a gradual increase in its inhibitor follistatin, followed during the second postnatal week by an increase in inhibins (Barakat et al. 2008). These studies indicate that activin A and its negative regulators follistatin and inhibins are tightly regulated during the first postnatal week and probably play a critical role in controlling the commitment of cells to differentiate. Further studies are required to determine more precisely the timing of activin A expression and the mechanisms mediating its effects on the fate decision of SSCs.

Although the main function of GDNF, a member of the TGFB superfamily acting via the two receptor system of GFRA 1 and RET, is to stimulate SSC self-renewal and survival, it has also been shown to promote differentiation in specific conditions (Meng et al. 2000). Indeed, GDNF expression levels are considered to play a pivotal role in controlling the fate of SSCs between self-renewal and differentiation, with high GDNF levels inducing SSCs self-renewal and low GDNF levels promoting differentiation (Meng et al. 2000). Other studies have demonstrated that the determination of which SSC undergoes self-renewal or differentiation is a completely random process that does not depend on its surrounding environment ( $\mathrm{Wu}$ et al. 2009). Several studies have converged to support the existence of a signaling network in which PLZF and GDNF could interact at the level of mTORC1 to prevent SSC commitment to differentiation. First, GDNF was shown to stimulate the PI3K/AKT pathway in spermatogonia (Braydich-Stolle et al. 2007). Then, GDNF was reported to activate mTORC1 in SSCs, which was shown to deplete the SSC pool by favoring SSC differentiation rather than self-renewal (Hobbs et al. 2010). The connection was provided in the same study, where PLZF was shown to prevent mTORC1 activation by inducing its inhibitor, Redd1, promoting self-renewal against differentiation. Another level of regulation was added through the ability of mTORC1 to inhibit AKT (Sabatini 2006). Finally, PLZF was reported to negatively interact with SALL4, a pluripotency transcription factor preferentially expressed in spermatogonial progenitor cells, where it induces differentiation, as well as in germ cell tumors (Hobbs et al. 2012). Another factor that might regulate spermatogonial progenitor cell differentiation is the epithelial cell adhesion molecule EPCAM, which was originally proposed as a marker for the enrichment of SSCs. Using transplantation assays, Kanatsu-Shinohara et al. showed that EPCAM $^{+}$-enriched cells contained 
a limited amount of cells with stem cell potential, contrary to germ cells enriched by flow cytometry for the tetraspanin $\mathrm{CD9}^{+}$that expressed stronger SSC potential. The study showed that EPCAM expression was increased in response to continuous exposure to GDNF, but not FGF2, in mouse spermatogonia. Moreover, overexpression of EPCAM in germ cells from Rosa mice did not affect their SSC potential in transplantation assays, while suppression of EPCAM increased the concentration of SSCs (Kanatsu-Shinohara et al. 2011). These findings implied that the suppression of EPCAM prevented spermatogonia from differentiating. The existence of these multi-layered signaling pathways, although not always identified in the same phase of spermatogonial development, illustrates how self-renewal and commitment to differentiation can be modulated at different interacting levels.

In search of factors involved in SSC differentiation, a study identified neuregulin 1 as inducing the formation of $A_{\text {aligned }}$ spermatogonia chains in rat, when used in combination with GDNF (Hamra et al. 2007). This study took advantage of the different fates of spermatogonia when grown on a monolayer of the MSC- 1 Sertoli cell line, which promotes stem cell maintenance, vs cells grown on the mouse embryonic fibroblastic SNL feeder layer cell line, which appears to induce differentiation. While the addition of exogenous GDNF alone to spermatogonia grown on Sertoli Cell-modified Laminin induced the formation of 4-8 cell chains, the simultaneous addition of GDNF and SNL cell-conditioned medium led to the formation of up to 32-cell long chains of $A_{\text {aligned }}$ spermatogonia. The purification and mass spectrometry analysis of the substance in the cellconditioned medium responsible for this effect revealed that it was neuregulin 1. Thus, neuregulin 1 was proposed to act in vitro as a spermatogonial amplification and differentiation factor in a GDNF-dependent manner, with GDNF targeting SSCs to become $A_{\text {paired }}$ and neuregulin inducing $A_{\text {paired }}$ to differentiate into $A_{\text {aligned }}$ spermatogonia. This effect was attributed to the binding of neuregulin 1 on neuregulin receptor ErbB3, complexed to ErbB2, both present in undifferentiated spermatogonia (Hamra et al. 2007).

The complexity of GDNF effects is further illustrated by studies showing that it can simultaneously promote SSC self-renewal and repress spermatogonial differentiation. This repressive effect on differentiation was proposed to be mediated by the GDNF-dependent upregulation of the expression of NUMB, a known repressor of $\mathrm{NOTCH}$. NOTCH signaling regulates stem cell fate choices and can promote stem cell self-renewal or differentiation, depending on the surrounding cues (Braydich-Stolle et al. 2005). NUMB inhibits the $\mathrm{NOTCH}$ pathway by interacting with activated $\mathrm{NOTCH}$ receptor (NICD), leading to its degradation. Thus, the GDNF-regulated production of NUMB may be an important factor in the maintenance of the SSC pool by inducing NOTCH1 degradation (Braydich-Stolle et al. 2005). GDNF is also important in maintaining the expression of NANOS2, which, as mentioned above, also prevents differentiation. Another key gene in the timing and extent of spermatogonial differentiation is Dmrt1, which was shown to repress the RA-induced transcription of Stra8, thus restricting the responsiveness of the cells to RA by limiting their differentiation to premeiotic changes (Matson et al. 2010). It is important to note that although factors such as BMP4, activin A, GDNF, and neuregulin 1 are probably involved in SSC differentiation, they must be properly controlled in order to keep a balance between the SSC self-renewal and differentiation processes.

In addition, Zheng et al. have recently used peptide tandem mass tag (TMT) labeling for the proteomics analysis of mouse neonatal testes from PND0.5PND5.5, in an effort to identify proteins specifically involved in early phases of mouse spermatogenesis. The comparison of these data with existing databases led to the identification of several potential candidate proteins possibly involved in gonocyte and SSC maturation. The germ cell expression of some of these proteins was confirmed by immunohistochemical analysis of PND3.5 and adult testes, identifying the presence of NUP153, SUZ12, and scaffold attachment factor B2 (SAFB2) in P3.5 undifferentiated spermatogonia, while whole-testes immunoblot analysis indicated their upregulation between PND3.5-PND5.5, suggesting potential roles in SSC maturation (Zheng et al. 2014). NUP153 is a nucleoporin protein that has not been previously shown to be involved in spermatogenesis. Nuclear transport of regulatory factors was proposed as a key regulatory process in germ cell differentiation (Hogarth et al. 2005). Thus, it is not surprising that such proteins would be involved in SSC differentiation. Interestingly, we have found by gene expression array analysis that Nup153 and Safb2 mRNAs are both expressed in PND3 gonocytes, at high level in the case of Nup153, suggesting that these genes might also play a role in gonocyte development (Manku and Culty, unpublished data). Furthermore, SUZ12 is a component of the polycomb repressive complex (PRC2) and Suz $12^{-1-}$ mice were found to have abnormal ESC differentiation. Thus, it is possible that a lack of SUZ12 would also negatively affect SSC differentiation. SAFB has previously been shown to be involved in SSC differentiation in rodents (Sergeant et al. 2007), in agreement with the postulate from the proteomic analysis.

Mouse SSCs are also able to transdifferentiate into hepatic-stem cell-like cells, which in turn, will differentiate into mature hepatocyte-like cells in vitro. This transdifferentiation requires activation of the ERK $1 / 2$ and Smad2/3 signaling pathways (Zhang et al. 2013b). Interestingly, we have previously shown that ERK $1 / 2$ activation is necessary for gonocyte proliferation, but that it does not participate in gonocyte differentiation 
(Thuillier et al. 2010, Manku et al. 2014). The ability of SSCs to transdifferentiate into mature hepatocytes is quite remarkable, illustrating the high plasticity of these unipotent stem cells, capable of reverting to pluripotency under specific conditions, representing potential clinical use in the treatment of liver diseases (Zhang et al. $2013 b)$. SSCs were proposed to have two potential therapeutic uses, one as a source of reprogrammable pluripotent stem cells that could be used for tissue regeneration (Nayernia 2007), the other as a reservoir of stem cells for the regeneration of spermatogenesis following cancer therapies (Valli et al. 2014).

Similar to gonocytes, in which WNT signaling pathways emerged as potentially involved in differentiation through miRNA studies, canonical and noncanonical WNT signaling pathways were proposed to play a role in spermatogonial functions. In particular, Wnt5a, probably produced by Sertoli cells, was shown to promote SSC survival and self-renewal via a noncanonical process while blocking $\beta$-catenin-dependent responses (Yeh et al. 2011), whereas WNT3A was found to be indirectly supporting SSCs by selectively stimulating the proliferation of progenitor spermatogonia committed to differentiation in a $\beta$-catenin-dependent manner (Yeh et al. 2012). These data suggest that WNT signaling pathways are involved both in gonocyte and spermatogonial functions, probably proliferation and differentiation, but further studies will be needed to clarify their exact functions.

Thus, although SSCs are an essential part of spermatogenesis, the processes and signaling mechanisms through which SSCs and other types of undifferentiated spermatogonia differentiate have not been sufficiently studied to fully comprehend the complexity of their regulation, due to their small cell number, SSCs being only $0.03 \%$ of the total testicular germ cells (Tegelenbosch \& de Rooij 1993), and the difficulty of conclusively distinguishing them from other undifferentiated spermatogonia. However, the recent advancements in this field suggest that new technologies should soon become available to better study SSC differentiation.

\section{Insights from non-rodent species}

Although the most common models in the study of spermatogenesis are rodents, other animals have been used, including boars, pigs, fish, worms, and fruit flies. A small numbers of studies have also been carried out on fetal to juvenile primates, including humans. The majority of these studies focused on developing methods to isolate and culture germ cells, transplantation assays of SSCs into recipient testes from autologous or heterologous species, or the determination of gene markers to classify various germ cell types. Despite being a growing field of research, few studies have been performed on the differentiation of gonocytes, SSCs, and spermatogonia in these non-traditional animal models.
Similarities in gene expression profiles between rodent and primate gonocytes have been reported, in support of using rodent models to study early germ cell development. However, most of these studies focused on pluripotency genes that were also retained in carcinoma in situ and TGCTs. Typical examples are the transcription factors NANOG, OCT4, TFAP2C (AP2 $\gamma$ ), and the miRNA-binding protein LIN28A, which are expressed not only in rodent and human fetal PGCs and gonocytes (Culty 2009, Weber et al. 2010), but also in testicular tumors (Hoei-Hansen et al. 2005, Rajpert-De Meyts 2006, Sonne et al. 2009, Gillis et al. 2011, Aeckerle et al. 2012). In mouse and human ESCs, both NANOG and OCT4 were found to belong to a protein network regulating cell pluripotency, which included also Wnt and its downstream target $\beta$-catenin (AbuRemaileh et al. 2010, Marucci et al. 2014). In ESCs, OCT4 was proposed to control ESC fate decision by inducing $\beta$-catenin degradation and preventing Wnt-regulated differentiation. As mentioned earlier, the role of the $\mathrm{Wnt} / \beta$-catenin pathway in spermatogonia is more complex. Interestingly, LIN28A was found to localize to the nuclei and cytosol of neonatal gonocytes, but to be restricted to the cytosol in spermatogonia, suggesting differential roles in gonocytes and spermatogonia (Gaytan et al. 2013). Moreover, despite their stem cell status, SSCs were found to express none or very little of NANOG, OCT4, and TFAP2C, while maintaining higher levels of two other ESC pluripotency genes, Thy 1 and Plzf (Culty 2009). These changes suggest that spermatogonial differentiation includes the active repression of selected pluripotency factors both in rodents and humans.

Given the limited availability of fetal and neonatal human testicular biopsies and the small numbers of germ cells that can be isolated from such samples, very few studies have examined the early steps of germ cell development in humans. At later ages, studies on SSCs have generally revolved around the maintenance of the SSC pool or the regeneration of spermatogenesis using SSCs isolated from pathological testes, after testicular insult/injury or chemotherapy treatments. Thus, although the steps leading to the formation of the SSC pool are critical for human spermatogenesis, these processes are seldom studied and the mechanisms that govern human gonocyte and spermatogonial differentiation are not well understood. Several studies have used primate models as surrogate for humans. Among them, studies in marmosets (Callithrix jacchus) have shown that germ cell differentiation occurs in a manner similar to that observed in humans, when analyzed at the level of common gene expression and cellular processes (Mitchell et al. 2008). At the molecular level, Mitchell et al. have shown that marmoset gonocyte differentiation results in decreased expression of the pluripotency markers OCT4 and NANOG and increase in VASA (DDX4) gene expression. Moreover, both humans and 
marmoset gonocyte differentiation occurred in an asynchronous manner within individual tubules (Mitchell et al. 2008). Thus, marmoset was proposed to be an ideal model to study gonocyte differentiation. However, the exact molecular mechanisms and signaling pathways of differentiation in the human and marmoset also remain yet to be determined.

Although they follow similar developmental patterns and appear to involve the same sets of genes/pathways overall, human and rodent spermatogenesis differs in some aspects of their fetal to neonatal developmental phases. A major difference is that rodent testis presents better temporal segregation of germ cell sub-types during perinatal periods than humans or marmosets do. Indeed, despite the heterogeneity of rodent gonocytes and spermatogonial populations, one can still define major developmental phases in which one germ cell type is dominant (Culty 2009, 2013). By contrast, in human and marmoset, a survey of available data on gene expression profiles, cell behaviors (e.g. proliferation or migration), and cell positioning within seminiferous cords (central vs basal location) clearly shows large overlaps of gonocyte and spermatogonial subpopulations for a period spreading from late gestation to early infancy (Sharpe et al. 2003, Franke et al. 2004, Gaskell et al. 2004, Pauls et al. 2006, Jørgensen et al. 2012, Ewen et al. 2013, McKinnell et al. 2013, O'Shaughnessy \& Fowler 2014).

Another difference resides in the fact that rodent gonocyte undergoes two phases of proliferation in the fetal and neonatal periods, respectively, separated by a proportionally long period of quiescence, whereas humans and marmosets lack this quiescent phase, and instead, one can find proliferative gonocytes in all periods surveyed, from gestation weeks (GWs) 12-14 until 2.5-4 months after birth in human, albeit at various levels (Hilscher \& Engemann 1992, Berensztein et al. 2002, Honecker et al. 2004, Ewen et al. 2013). Overall, these studies reported the highest rates of proliferation between the third and fifth gestation months, followed by decreased proliferation in late gestation and a small increase in proliferation in 2.5- to 6-month-old infants. Thus, despite the lack of total quiescence, human fetal gonocytes present a period of minimal proliferation similar to the quiescence phase observed in rodents. Moreover, it is interesting to note that the late gestation period of low proliferation in human fetal gonocytes partially overlaps with the phase of highest DNA methyl transferase expression (GW21-GW29), strikingly reminiscent of the high DNA methylation activities observed during late gestation in rodent gonocytes (Galetzka et al. 2007). In marmoset, in which gestation lasts 22 weeks, similar fluctuations in proliferation rates were observed, with maximal proliferation at GW11-GW14, a decrease at GW15-GW16, followed by an increase to $40 \%$ of proliferating gonocytes at GW17-GW20, and a return to a lower rate until 6 weeks after birth (Mitchell et al.
2008). A subsequent study by the same group concurred with a proliferation index of $29 \%$ in GW12-GW17 fetal gonocytes, decreasing to values of $\sim 10 \%$ in infants from the first postnatal week to 5 months (McKinnell et al. 2013). Interestingly, we have observed an in vivo proliferation rate of $\sim 30 \%$ in PND3 rats, similar to the values found in marmoset late fetal testes (Thuillier et al. 2009). Taken together, the transient decrease in proliferation rates and the concomitant high levels of DNA methylation in late gestation suggest that this period in human germ cell development is comparable to the fetal quiescent phase observed in rodents.

Another important discriminatory factor during gonocyte development is whether or not they have reached the basement membrane of the tubules, a prerequisite to differentiation. In rat, it is very rare to see a gonocyte not centrally located at PND3, whereas this can happen earlier in mice. This is very different from human and marmoset, in which germ cell relocation can be observed already in utero. In GW15-GW18 human testes, the quantification of more differentiated $\mathrm{Vasa}^{+}(30 \%$ of total gonocytes) and more pluripotent $\mathrm{Oct}^{+}$gonocytes $(70 \%$ of total gonocytes), located either centrally or basally within the tubules, showed that one out of three Oct ${ }^{+}$cells had already relocated to the basement membrane, as well as two out of three $\mathrm{Vasa}^{+}$cells (McKinnell et al. 2013). In marmoset, there were $26 \%$ of $\mathrm{Vasa}^{+}$gonocytes located at the base of the tubules at GW12-GW17, while at birth, 31\% of gonocytes were at the basement membrane (McKinnell et al. 2013). However, at postnatal weeks 18-24 (early infancy), there were still $56 \%$ of the cells with a typical gonocyte morphology centrally located, and their total numbers had increased by several fold, demonstrating the continuation of proliferation up to 6 months of age (Sharpe et al. 2003, McKinnell et al. 2013). These various studies provided indirect benchmarks on the timing of gonocyte and spermatogonial differentiation in comparison to rodents, and highlighted genes acting as potential gatekeepers that may need to be repressed for differentiation to proceed.

The study of gonocytes in Mongolian gerbils (Meriones unguiculatus) has revealed that, similar to rats, gonocytes must migrate to the seminiferous tubule basement membrane in order to differentiate. However, in the gerbil, the relocation period is much longer, extending to the second postnatal week (Pinto et al. 2010). This relocation also occurs simultaneously with a loss in androgen sensitivity (Pinto et al. 2010). The pig is another animal model in which early steps of germ cell development have been studied, because of their potential use in derivating pluripotent cells for the generation of transgenic farm animals (Alberio \& Perez 2012). In pigs, gonocytes will proliferate, migrate to the basement membrane of the tubules, and differentiate to SSCs during the first 3 months of life. These gonocytes can be identified by the marker dolichos biflorus agglutinin 


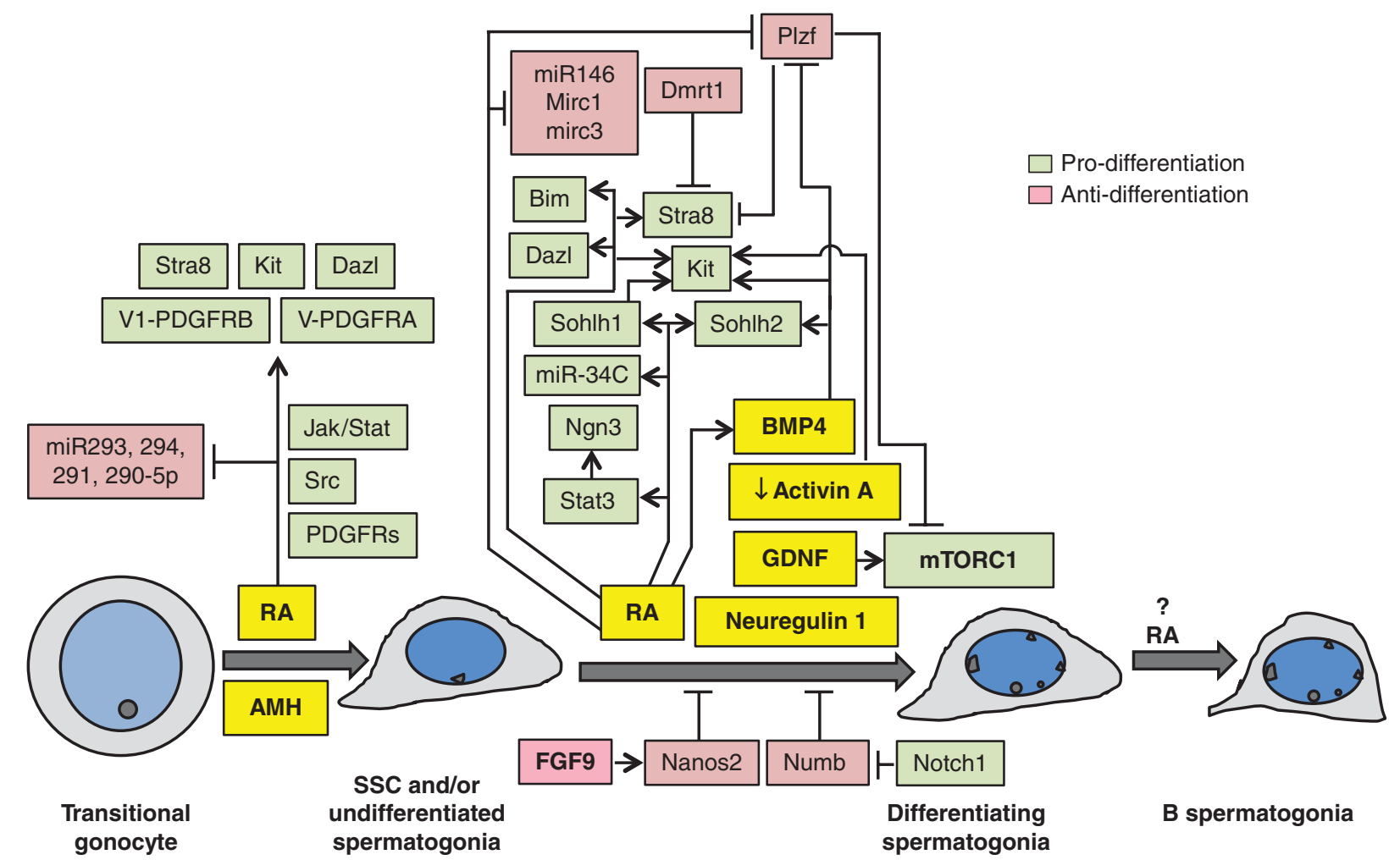

Figure 1 Summary diagram of the factors regulating transitional gonocyte and spermatogonial differentiation. In both cases, RA induces differentiation. Additional factors shown to induce gonocyte or spermatogonial differentiation are also shown. Green boxes: genes/proteins positively involved in differentiation. Red boxes: genes/proteins negatively involved in differentiation. Arrows with regular arrow heads indicate a positive regulation. Arrows with a blunt end indicate inhibition/negative regulation. Although SSCs and undifferentiated spermatogonia are combined for simplicity, effectors/pathways that are specific for the transition from SSCs to a more advanced phase of undifferentiated spermatogonia, or from undifferentiated to differentiating spermatogonia are described in more details in the text and Table 1.

(DBA), highly expressed not only before PND14, but also during gonocyte differentiation between 2 and 3 weeks of age and in subsets of spermatogonia (Klisch et al. 2011, Kim et al. 2013). Germ cells from 2- to 3-week-old, but not younger, prepubertal pigs also expressed stagespecific embryonic antigen 1 (SSEA1; Goel et al. 2007). Using SSEA1-FACS enrichment coupled to xenotransplantation assays, Kim et al. (2013) proposed that SSEA1 is a marker of undifferentiated pig spermatogonia, including SSCs. Approximately half of SSEA1 enriched cells co-expressed Uchl1 (ubiquitin carboxyl-terminal esterase L1/PGP 9.5) and more than $40 \%$ expressed the undifferentiated spermatogonial marker PLZF, as well as VASA, considered as an SSC differentiation marker in boars (Luo et al. 2009). In this model, Thy1, CD9, and $\alpha 6-\beta 1$-integrins appeared less effective for spermatogonial enrichment than they are in rodent models, suggesting differences in SSC markers between porcine and rodent models. Moreover, the mechanisms regulating porcine gonocytes and SSC differentiation are not understood yet.

A commonly used model for the study of germline stem cell (GSC) development is the Drosophila (see reviews by de Cuevas \& Matunis (2011) and Spradling et al. (2011)). In this invertebrate, GSC formation from
PGCs relies on PGC migration, coinciding with gonad formation and the establishment of the hub, an embryonic center formed by somatic gonadal precursor cells located at the apex of the testes. Studies have shown that the Jak/Stat pathway activation is involved in PGC migration into the vicinity of the hub, where they will become GSCs, and that only germ cells with active Jak/ Stat will form polarized adherent junctions with hub cells, defining the stem cell niche microenvironment essential for the maintenance of GSC self-renewal. Jak/ Stat was found to be necessary for GSC maintenance, and to prevent further differentiation (Sheng et al. 2009). Differentiation appears to be regulated by interactions between germ cells and the cyst cells surrounding them. Early germ cells were shown to produce Spitz, an EGF receptor (EGFR) ligand, which acts on EGFRs on cyst cells, leading to MAPK activation and the promotion of germ cell differentiation. One of the genes involved in differentiation is Bam (bag of marbles). On the other end, cyst cells produce TGF $\beta$, which prevents Bam expression and differentiation (Davies \& Fuller 2008). These animal models have also been instrumental in revealing the critical role of epigenetic processes such as chromatin remodeling and histone modifications in the regulation of germ cell differentiation (review in Eun et al. (2010)). 
Table 1 Summary of genes/proteins/pathways involved in gonocytes or spermatogonial differentiation.

\begin{tabular}{|c|c|c|c|c|c|}
\hline Cell type & Species & Gene/pathway & Function & Effect & References \\
\hline \multirow[t]{9}{*}{$\begin{array}{l}\text { Neonatal } \\
\text { gonocytes }\end{array}$} & $\mathrm{m}$ & $\mathrm{NOTCH} 1$ & $\begin{array}{l}\text { Overexpression in fetal gonocytes leads } \\
\text { to premature differentiation: } \uparrow \text { Kit, } \\
\uparrow \text { SOHLH2 }\end{array}$ & + & $\begin{array}{l}\text { Dirami et al. (2001) and } \\
\text { Garcia et al. (2013) }\end{array}$ \\
\hline & $\mathrm{m}, \mathrm{r}$ & RA, RAR & $\begin{array}{l}\uparrow \text { Differentiation; } \uparrow \text { Stra8, } \uparrow \text { V1-PDGFRB, } \\
\uparrow \text { Dazl, } \uparrow \text { Kit }\end{array}$ & + & $\begin{array}{l}\text { Wang \& Culty }(2007) \text { and } \\
\text { Zhou et al. }(2008 a, b)\end{array}$ \\
\hline & r & Proteasome activity & Required for RA-induced differentiation & + & Manku et al. (2012) \\
\hline & $r$ & Variant V1-PDGFRB & $\uparrow$ By RA; overexpression $\uparrow$ Stra8 expression & + & $\begin{array}{l}\text { Sarkar, Manku and Culty } \\
\quad \text { (unpublished data) }\end{array}$ \\
\hline & $\mathrm{r}$ & Variant PDGFRA & $\uparrow$ By RA, unknown function & + & Manku et al. (2014) \\
\hline & $r$ & SRC, Jak2/Stat5 & $\begin{array}{l}\text { Activity required for RA-induced } \\
\text { differentiation }\end{array}$ & + & Manku et al. (2014) \\
\hline & $\mathrm{m}$ & MIS/AMH & $\uparrow$ Differentiation to type A spermatogonia & + & Zhou \& Hutson (1995) \\
\hline & $\mathrm{m}$ & $\begin{array}{l}\text { miR293, 294, 291, } \\
\text { 290-5p }\end{array}$ & $\begin{array}{l}\text { miRNA clusters downregulated during } \\
\text { differentiation regulate PTEN and } \\
\text { Wnt/ } \beta \text {-catenin pathways } \\
\text { Pathways converging on cyclin D1 }\end{array}$ & - & Mclver et al. (2012) \\
\hline & $r$ & Nup153 and Safb2 & Strong mRNA expression & $?$ & $\begin{array}{l}\text { Manku and Culty (unpub- } \\
\text { lished observations) }\end{array}$ \\
\hline \multirow[t]{17}{*}{$\begin{array}{l}\text { Spermatogonia } \\
\text { SSCs }\end{array}$} & $\mathrm{m}, \mathrm{r}$ & RA, RAR & $\begin{array}{l}\text { SSCs to undifferentiated, progenitors to } \\
\text { differentiated }\end{array}$ & + & $\begin{array}{l}\text { Schrans-Stassen et al. (1999) } \\
\text { and Zhou et al. }(2008 a, b)\end{array}$ \\
\hline & $\mathrm{m}$ & $\begin{array}{l}\text { Stra8, Kit, Sohlh2, } \\
\text { Bim, Dazl }\end{array}$ & Progression from SSCs to differentiating cells & + & Tong et al. (2012) \\
\hline & $\mathrm{m}$ & Sohlh1 & Increases Kit expression & + & $\begin{array}{l}\text { Barrios et al. (2012), Oatley \& } \\
\text { Brinster (2012), and Suzuki } \\
\text { et al. (2012) }\end{array}$ \\
\hline & $\mathrm{m}$ & miR-34C & $\begin{array}{l}\downarrow \text { Nanos2, } \uparrow \text { differentiation, } \uparrow \text { Nanos3, } \\
\uparrow \text { Stra8 }\end{array}$ & + & Yu et al. (2014) \\
\hline & $r$ & BMP4 & $\begin{array}{l}\text { Increased by RA, } \uparrow \text { SSC differentiation, } \\
\uparrow \text { SMAD1/5/8 activation, } \uparrow \text { Sohlh2, } \\
\uparrow \text { Kit, } \downarrow \text { PLZF }\end{array}$ & + & Carlomagno et al. (2010) \\
\hline & $\mathrm{m}$ & Decreased activin A & $\begin{array}{l}\uparrow \text { Recruitment of cells to differentiation, } \\
\uparrow \text { Kit }\end{array}$ & + & Nagano et al. (2003) \\
\hline & $\mathrm{m}, \mathrm{r}$ & Low level GDNF & Promotes SSC to $A_{\text {pair }}$ differentiation & + & $\begin{array}{l}\text { Meng et al. (2000) and Hamra } \\
\text { et al. (2007) }\end{array}$ \\
\hline & $r$ & Neuregulin 1 & Promotes $A_{\text {paired }}$ to $A_{\text {aligned }}$ differentiation & + & Hamra et al. (2007) \\
\hline & $\mathrm{m}$ & STAT3 & Induces Ngn3 expression & + & Oatley et al. (2010) \\
\hline & $\mathrm{m}$ & Ngn3/Neurog & $\begin{array}{l}\text { SSC to undifferentiated, transit amplifying } \\
\text { progenitors }\end{array}$ & + & Kaucher et al. (2012) \\
\hline & $\mathrm{m}$ & PLZF & $\begin{array}{l}\text { In SSC to undifferentiated. Blocks Kit, SALL4, } \\
\text { TORC1 }\end{array}$ & - & Buaas et al. (2004) \\
\hline & $\mathrm{m}$ & Nanos2 & Regulated by Fgf9, prevents differentiation & - & $\begin{array}{l}\text { Barrios et al. (2010) and Sada } \\
\quad \text { et al. (2012) }\end{array}$ \\
\hline & $\mathrm{m}$ & Numb & Represses Notch1, $\downarrow$ differentiation & - & Braydich-Stolle et al. (2005) \\
\hline & $\mathrm{m}$ & $\begin{array}{l}\text { Mirc1, Mirc3 } \\
\text { clusters }\end{array}$ & Negative regulators, $\downarrow$ by RA & - & Tong et al. (2012) \\
\hline & $\mathrm{m}$ & miR-146 & Negative regulators, $\downarrow$ by RA & - & Huszar \& Payne (2013) \\
\hline & $\mathrm{m}$ & DMRT1 & $\begin{array}{l}\text { Represses Stra8 transcription; restricts } \\
\text { RA responsiveness }\end{array}$ & - & Matson et al. (2010) \\
\hline & $\mathrm{m}$ & $\begin{array}{l}\text { Nup153, Suz12, } \\
\text { Safb2 }\end{array}$ & $\begin{array}{l}\uparrow \text { Expression at PND3.5; in cells at } \\
\text { basement membrane; in undifferentiated } \\
\text { spermatogonia }\end{array}$ & $+?$ & Zheng et al. (2014) \\
\hline
\end{tabular}

Upward pointing arrows indicate increased expression of a gene/protein or increased function. Downward pointing arrows indicate decreased expression of a gene/protein or suppressed function.

Although there is no defined 'gonocyte' stage in Drosophila, the postmigratory germ cells that make connections to hub cells and become GSCs demonstrate a behavior similar to the neonatal migratory gonocytes that need to establish contact with the basement membrane of the seminiferous cords in order to differentiate into SSCs. As mentioned earlier, we have recently found that Jak/Stat activation is required for RA-induced gonocyte differentiation in vitro (Manku et al. 2014). By analogy with the Drosophila model, it would be interesting to determine whether Jak/Stat activation is involved in the cell adhesion processes allowing the anchoring of migratory gonocytes in the future niche, where they can become spermatogonia.

\section{Conclusion}

By presenting the state of the current knowledge on the mechanisms regulating gonocyte and spermatogonial differentiation (Fig. 1), this review emphasizes the broad gaps left in our understanding of these cells and the lack of available literature on these topics. Although the 
development of these early germ cells dictates the subsequent status of spermatogenesis, the paucity of transitional gonocytes and SSCs within testes, together with the absence of specific markers for these phases of germ cell development, have hindered the pace of new findings in this field of research. Nonetheless, strides have been made, unveiling different genes and pathways that are critical for the differentiation of both cell types. The comparison of these processes also stressed how they involve different proteins and signaling pathways, despite both responding to RA (Table 1). This further suggests that the fine tuning and regulation of differentiation in time and space are carried out through crosstalk mechanisms between RA and other factors. However, more work needs to be carried out to determine how all of these pieces fit together to regulate proper early germ cell differentiation.

\section{Declaration of interest}

The authors declare that there is no conflict of interest that could be perceived as prejudicing the impartiality of the review.

\section{Funding}

The authors were supported in part by a NSERC Discovery grant (no. 386038-2013) and a grant from the Canadian Institutes of Health Research (CIHR) (no. MOP-312268) to M Culty. The Research Institute of MUHC is supported in part by a Center grant from Le Fonds de la Recherche en Santé du Quebec (FRSQ).

\section{References}

Abu-Remaileh M, Gerson A, Farago M, Nathan G, Alkalay I, Zins Rousso S, Gur M, Fainsod A \& Bergman Y 2010 Oct-3/4 regulates stem cell identity and cell fate decisions by modulating $\mathrm{Wnt} / \beta$-catenin signalling. EMBO Journal 29 3236-3248. (doi:10.1038/emboj.2010.200)

Adler ID 1996 Comparison of the duration of spermatogenesis between male rodents and humans. Mutation Research 352 169-172. (doi:10.1016/0027-5107(95)00223-5)

Aeckerle N, Eildermann K, Drummer C, Ehmcke J, Schweyer S, Lerchl A, Bergmann M, Kliesch S, Gromoll J, Schlatt S et al. 2012 The pluripotency factor LIN28 in monkey and human testes: a marker for spermatogonial stem cells? Molecular Human Reproduction 18 477-488. (doi:10.1093/ molehr/gas025)

Ahluwalia B \& Bieri JG 1971 Local stimulatory effect of vitamin A on spermatogenesis in the rat. Journal of Nutrition 101 141-151.

Akmal KM, Dufour JM \& Kim KH 1997 Retinoic acid receptor $\alpha$ gene expression in the rat testis: potential role during the prophase of meiosis and in the transition from round to elongating spermatids. Biology of Reproduction 56 549-556. (doi:10.1095/biolreprod56.2.549)

Alberio R \& Perez AR 2012 Recent advances in stem and germ cell research: implications for the derivation of pig pluripotent cells. Reproduction in Domestic Animals 47 (Suppl 4) 98-106. (doi:10.1111/j.1439-0531. 2012.02062.x)

Amman RP \& Howards SS 1980 Daily spermatozoal production and epididymal spermatozoal reserves of the human male. Journal of Urology 124 211-215.
Anderson EL, Baltus AE, Roepers-Gajadien HL, Hassold TJ, de Rooij DG, van Pelt AM \& Page DC 2008 Stra8 and its induced, retinoic acid, regulate meiotic initiation in both spermatogenesis and oogenesis in mice. PNAS 105 14976-14980. (doi:10.1073/pnas.0807297105)

Baltus AE, Menke DB, Hu YC, Goodheart ML, Carpenter AE, de Rooij DG \& Page DC 2006 In germ cells of mouse embryonic ovaries, the decision to enter meiosis precedes premeiotic DNA replication. Nature Genetics 38 1430-1434. (doi:10.1038/ng1919)

Barakat B, O'Connor AE, Gold E, de Kretser DM \& Loveland KL 2008 Inhibin, activin, follistatin and FSH serum levels and testicular production are highly modulated during the first spermatogenic wave in mice. Reproduction 136 345-359. (doi:10.1530/REP-08-0140)

Barrios F, Filipponi D, Pellegrini M, Paronetto MP, Di Siena S, Geremia R, Rossi P, De Felici M, Jannini EA \& Dolci S 2010 Opposing effects of retinoic acid and FGF9 on Nanos2 expression and meiotic entry of mouse germ cells. Journal of Cell Science 123 871-880. (doi:10.1242/ jcs.057968)

Barrios F, Filipponi D, Campolo F, Gori M, Bramucci F, Pellegrini M, Ottolenghi S, Rossi P, Jannini EA \& Dolci S 2012 SOHLH1 and SOHLH2 control kit expression during postnatal male germ cell development. Journal of Cell Science 125 1455-1464. (doi:10.1242/jcs.092593)

Basciani S, De Luca G, Dolci S, Brama M, Arizzi M, Mariani S, Rosano G, Spera G \& Gnessi L 2008 Platelet-derived growth factor receptor $\beta$-subtype regulates proliferation and migration of gonocytes. Endocrinology 149 6226-6235. (doi:10.1210/en.2008-0349)

Bellve AR, Millette CF, Bhatnagar YM \& O'Brien DA 1977 Dissociation of the mouse testis and characterization of isolated spermatogenic cells. Journal of Histochemistry and Cytochemistry 25 480-494. (doi:10.1177/ 25.7.893996)

Berensztein EB, Sciara MI, Rivarola MA \& Belgorosky A 2002 Apoptosis and proliferation of human testicular somatic and germ cells during prepuberty: high rate of testicular growth in newborns mediated by decreased apoptosis. Journal of Clinical Endocrinology and Metabolism 87 5113-5118. (doi:10.1210/jc.2002-020032)

Bouillet P, Oulad-Abdelghani M, Vicaire S, Garnier JM, Schuhbaur B, Dolle P \& Chambon P 1995 Efficient cloning of cDNAs of retinoic acidresponsive genes in P19 embryonal carcinoma cells and characterization of a novel mouse gene, Stra1 (mouse LERK-2/Eplg2). Developmental Biology 170 420-433. (doi:10.1006/dbio.1995.1226)

Boulogne B, Levacher C, Durand P \& Habert R 1999 Retinoic acid receptors and retinoid $X$ receptors in the rat testis during fetal and postnatal development: immunolocalization and implication in the control of the number of gonocytes. Biology of Reproduction 61 1548-1557. (doi:10.1095/biolreprod61.6.1548)

Braydich-Stolle L, Nolan C, Dym M \& Hofmann MC 2005 Role of glial cell line-derived neurotrophic factor in germ-line stem cell fate. Annals of the New York Academy of Sciences 1061 94-99. (doi:10.1196/annals. 1336.010)

Braydich-Stolle L, Kostereva N, Dym M \& Hofmann MC 2007 Role of Src family kinases and $\mathrm{N}-\mathrm{Myc}$ in spermatogonial stem cell proliferation. Developmental Biology 304 34-45. (doi:10.1016/j.ydbio.2006.12.013)

Brinster RL \& Avarbock MR 1994 Germline transmission of donor haplotype following spermatogonial transplantation. PNAS 91 11303-11307. (doi:10.1073/pnas.91.24.11303)

Brinster RL \& Zimmermann JW 1994 Spermatogenesis following male germ-cell transplantation. PNAS 91 11298-11302. (doi:10.1073/pnas. 91.24.11298)

Buaas FW, Kirsh AL, Sharma M, McLean DJ, Morris JL, Griswold MD, de Rooij DG \& Braun BE 2004 Plzf is required in adult male germ cells for stem cell self-renewal. Nature Genetics 36 647-652. (doi:10.1038/ng1366)

Carlomagno G, van Bragt MP, Korver CM, Repping S, de Rooij DG \& van Pelt AM 2010 BMP4-induced differentiation of a rat spermatogonial stem cell line causes changes in its cell adhesion properties. Biology of Reproduction 83 742-749. (doi:10.1095/biolreprod.110.085456)

Christensen AK 1975 Leydig cells. In Handbook of Physiology, Section 7: Endocrinology, Volume 5, Male Reproductive System, pp 57-94. RO Greep and DW Hamilton Eds. American Physiological Society (Lippincott Williams and Wilkins; Washington D.C.)

Clermont Y \& Perey B 1957 Quantitative study of the cell population of the seminiferous tubules in immature rats. American Journal of Anatomy 100 241-267. (doi:10.1002/aja.1001000205) 
Collins MD \& Mao GE 1999 Teratology of retinoids. Annu Rev Pharmacol Toxicol 39 399-430.

Corney DC, Flesken-Nikitin A, Godwin AK, Wang W \& Nikitin AY 2007 MicroRNA-34b and microRNA-34c are targets of p53 and cooperate in control of cell proliferation and adhesion-independent growth. Cancer Research 67 8433-8438. (doi:10.1158/0008-5472.CAN-07-1585)

de Cuevas M \& Matunis EL 2011 The stem cell niche: lessons from the Drosophila testis. Development 138 2861-2869. (doi:10.1242/dev. 056242)

Culty M 2009 Gonocyte, the forgotten cells of the germ cell lineage. Birth Defects Research. Part C, Embryo Today: Reviews 87 1-26. (doi:10.1002/ bdrc.20142)

Culty M 2013 Gonocytes, from the fifties to the present: is there a reason to change the name? Biology of Reproduction 46 1-6.

Davies EL \& Fuller MT 2008 Regulation of self-renewal and differentiation in adult stem cell lineages: lessons from the Drosophila male germ line. Cold Spring Harbor Symposia on Quantitative Biology 73 137-145. (doi:10.1101/sqb.2008.73.063)

Dirami G, Ravindranath N, Achi MV \& Dym M 2001 Expression of Notch pathway components in spermatogonia and Sertoli cells of neonatal mice. Journal of Andrology 22 944-952.

Drayer AL, Boer AK, Los EL, Esselink MT \& Vellenga E 2005 Stem cell factor synergistically enhances thrombopoietin-induced STAT5 signaling in megakaryocyte progenitors through JAK2 and Src kinase. Stem Cells 23 240-251. (doi:10.1634/stemcells.2004-0153)

Eun SH, Gan Q \& Chen X 2010 Epigenetic regulation of germ cell differentiation. Current Opinion in Cell Biology 22 737-743. (doi:10. 1016/j.ceb.2010.09.004)

Ewen KA, Olesen IA, Winge SB, Nielsen AR, Nielsen JE, Graem N, Juul A \& Rajpert-De Meyts E 2013 Expression of FGFR3 during human testis development and in germ cell-derived tumours of young adults. International Journal of Developmental Biology 57 141-151. (doi:10. 1387/ijdb.130022er)

Filipponi D, Hobbs RM, Ottolenghi S, Rossi P, Jannini EA, Pandolfi PP \& Dolci S 2007 Repression of kit expression by Plzf in germ cells. Molecular and Cellular Biology 27 6770-6781. (doi:10.1128/MCB.00479-07)

Franke FE, Pauls K, Rey R, Marks A, Bergmann M \& Steger K 2004 Differentiation markers of Sertoli cells and germ cells in fetal and early postnatal human testis. Anatomy and Embryology 209 169-177.

Galetzka D, Weis E, Tralau T, Seidmann L \& Haaf T 2007 Sex-specific windows for high mRNA expression of DNA methyltransferases 1 and $3 \mathrm{~A}$ and methyl-CpG-binding domain proteins 2 and 4 in human fetal gonads. Molecular Reproduction and Development 74 233-241. (doi:10.1002/mrd.20615)

Garcia TX \& Hofmann MC 2013 NOTCH signaling in Sertoli cells regulates gonocyte fate. Cell Cycle 12 2538-2545. (doi:10.4161/cc.25627)

Garcia TX, de Falco T, Capel B \& Hofmann MC 2013 Constitutive activation of NOTCH1 signaling in Sertoli cells causes gonocyte exit from quiescence. Developmental Biology 377 188-201. (doi:10.1016/j.ydbio.2013.01.031)

Gaskell TL, Esnal A, Robinson LL, Anderson RA \& Saunders PT 2004 Immunohistochemical profiling of germ cells within the human fetal testis: identification of three subpopulations. Biology of Reproduction $\mathbf{7 1}$ 2012-2021. (doi:10.1095/biolreprod.104.028381)

Gaytan F, Sangiao-Alvarellos S, Manfredi-Lozano M, García-Galiano D, Ruiz-Pino F, Romero-Ruiz A, León S, Morales C, Cordido F, Pinilla L et al. 2013 Distinct expression patterns predict differential roles of the miRNAbinding proteins, Lin28 and Lin28b, in the mouse testis: studies during postnatal development and in a model of hypogonadotropic hypogonadism. Endocrinology 154 1321-1336. (doi:10.1210/en.2012-1745)

Gely-Pernot A, Raverdeau $M$, Célébi $C$, Dennefeld C, Feret B, Klopfenstein M, Yoshida S, Ghyselinck NB \& Mark M 2012 Spermatogonia differentiation requires retinoic acid receptor $\gamma$. Endocrinology 153 438-449. (doi:10.1210/en.2011-1102)

Ghyselinck NB, Vernet N, Dennefeld C, Giese N, Nau H, Chambon P, Viville S \& Mark M 2006 Retinoids and spermatogenesis: lessons from mutant mice lacking the plasma retinol binding protein. Developmental Dynamics 235 1608-1622. (doi:10.1002/dvdy.20795)

Gillis AJ, Stoop H, Biermann K, van Gurp RJ, Swartzman E, Cribbes S, Ferlinz A, Shannon M, Oosterhuis JW \& Looijenga LH 2011 Expression and interdependencies of pluripotency factors LIN28, OCT3/4, NANOG and SOX2 in human testicular germ cells and tumours of the testis. International Journal of Andrology 34 e160-e174. (doi:10.1111/j.13652605.2011.01148.x)

Giuili G, Tomljenovic A, Labrecque N, Oulad-Abdelghani M, Rassoulzadegan M \& Cuzin F 2002 Murine spermatogonial stem cells: targeted transgene expression and purification in an active state. $E M B O$ Reports 3 753-759. (doi:10.1093/embo-reports/kvf149)

Goel S, Sugimoto M, Minami N, Yamada M, Kume S \& Imai H 2007 Identification, isolation, and in vitro culture of porcine gonocytes. Biology of Reproduction 77 127-137. (doi:10.1095/biolreprod.106.056879)

Griswold MD, Bishop PD, Kim KH, Ping R, Siiteri JE \& Morales C 1989 Function of vitamin A in normal and synchronized seminiferous tubules. Annals of the New York Academy of Sciences 564 154-172. (doi:10. 1111/j.1749-6632.1989.tb25895.x)

Hamra FK, Chapman KM, Nguyen D \& Garbers DL 2007 Identification of neuregulin as a factor required for formation of aligned spermatogonia. Journal of Biological Chemistry 282 721-730. (doi:10.1074/jbc. M608398200)

Hao J, Yamamoto M, Richardson TE, Chapman KM, Denard BS, Hammer RE, Zhao GQ \& Hamra FK 2008 Sohlh2 knockout mice are male-sterile because of degeneration of differentiating type A spermatogonia. Stem Cells 26 1587-1597. (doi:10.1634/stemcells.2007-0502)

Hermann BP, Phillips BT \& Orwig KE 2011 The elusive spermatogonial stem cell marker? Biology of Reproduction 85 221-223. (doi:10.1095/ biolreprod.111.093146)

Hermo L, Pelletier R, Cyr DG \& Smith CE 2010 Surfing the wave, cycle, life history, and genes/proteins expressed by testicular germ cells. Part 1: background to spermatogenesis, spermatogonia, and spermatocytes. Microscopy Research and Technique 73 241-278. (doi:10.1002/jemt.20783)

Hilscher B \& Engemann A 1992 Histological and morphometric studies on the kinetics of germ cells and immature Sertoli cells during human prespermatogenesis. Andrologia 24 7-10. (doi:10.1111/j.1439-0272. 1992.tb02600.x)

Hobbs RM, Seandel M, Falciatori I, Rafii S \& Pandolfi PP 2010 Plzf regulates germline progenitor self-renewal by opposing mTORC1. Cell 142 468-479. (doi:10.1016/j.cell.2010.06.041)

Hobbs RM, Fagoonee S, Papa A, Webster K, Altruda F, Nishinakamura R, Chai L \& Pandolfi PP 2012 Functional antagonism between Sall4 and Plzf defines germline progenitors. Cell Stem Cell 10 284-298. (doi:10.1016/j.stem.2012.02.004)

Hoei-Hansen CE, Almstrup K, Nielsen JE, Brask Sonne S, Graem N, Skakkebaek NE, Leffers H \& Rajpert-De Meyts E 2005 Stem cell pluripotency factor NANOG is expressed in human fetal gonocytes, testicular carcinoma in situ and germ cell tumours. Histopathology $\mathbf{4 7}$ 48-56.

Hogarth CA \& Griswold MD 2010 The key role of vitamin A in spermatogenesis. Journal of Clinical Investigation 120 956-962. (doi:10.1172/JCl41303)

Hogarth CA \& Griswold MD 2013 Retinoic acid regulation of male meiosis. Current Opinion in Endocrinology, Diabetes, and Obesity 20 217-223. (doi:10.1097/MED.0b013e32836067cf)

Hogarth C, Itman C, Jans DA \& Loveland KL 2005 Regulated nucleocytoplasmic transport in spermatogenesis: a driver of cellular differentiation? BioEssays 27 1011-1025. (doi:10.1002/bies.20289)

Honecker F, Stoop H, de Krijger RR, Chris Lau YF, Bokemeyer C \& Looijenga LH 2004 Pathobiological implications of the expression of markers of testicular carcinoma in situ by fetal germ cells. Journal of Pathology 203 849-857. (doi:10.1002/path.1587)

Huang HF, Durenfurth I \& Hembree WC 1983 Endocrine changes associated with germ cell loss during vitamin A deficiency and vitamin-A induced recovery of spermatogenesis. Endocrinology 112 1163-1171. (doi:10.1210/endo-112-4-1163)

Huang Z, Rivas B \& Agoulnik AI 2013 NOTCH1 gain of function in germ cells causes failure of spermatogenesis in male mice. PLOS ONE 8 e71213. (doi:10.1371/journal.pone.0071213)

Huszar JM \& Payne CJ 2013 MicroRNA 146 (Mir146) modulates spermatogonial differentiation by retinoic acid in mice. Biology of Reproduction 88 15. (doi:10.1095/biolreprod.112.103747)

Huyghe E, Matsuda T \& Thonneau P 2003 Increasing incidence of testicular cancer worldwide: a review. Journal of Urology 170 5-11. (doi:10.1097/ 01.ju.0000053866.68623.da) 
Jameson SA, Natarajan A, Cool J, DeFalco T, Maatouk DM, Mork L, Munger SC \& Capel B 2012 Temporal transcriptional profiling of somatic and germ cells reveals biased lineage priming of sexual fate in the fetal mouse gonad. PLoS Genetics 8 e1002575. (doi:10.1371/journal.pgen. 1002575)

Jan SZ, Hamer G, Repping S, de Rooij DG, van Pelt AM \& Vormer TL 2012 Molecular control of rodent spermatogenesis. Biochimica et Biophysica Acta 1822 1838-1850. (doi:10.1016/j.bbadis.2012.02.008)

Jørgensen A, Nielsen JE, Jensen MB, Græm N \& Rajpert-De Meyts E 2012 Analysis of meiosis regulators in human gonads: a sexually dimorphic spatio-temporal expression pattern suggests involvement of DMRT1 in meiotic entry. Molecular Human Reproduction 18 523-534.

Kanatsu-Shinohara M, Takashima S, Ishii K \& Shinohara T 2011 Dynamic changes in EPCAM expression during spermatogonial stem cell differentiation in the mouse testis. PLOS ONE 6 e23663. (doi:10.1371/ journal.pone.0023663)

Kaucher AV, Oatley MJ \& Oatley JM 2012 NEUROG3 is a critical downstream effector for STAT3-regulated differentiation of mammalian stem and progenitor spermatogonia. Biology of Reproduction 86164. (doi:10.1095/biolreprod.111.097386)

Kawaguchi R, Yu J, Honda J, Hu J, Whitelegge J, Ping P, Wiita P, Bok D \& Sun H 2007 A membrane receptor for retinol binding protein mediates cellular uptake of vitamin A. Science 315 820-825. (doi:10.1126/ science.1136244)

Kim YH, Kim BJ, Kim BG, Lee YA, Kim KJ, Chung HJ, Hwang S, Woo JS, Park JK, Schmidt JA et al. 2013 Stage-specific embryonic antigen-1 expression by undifferentiated spermatogonia in the prepubertal boar testis. Journal of Animal Science 91 3143-3154. (doi:10.2527/jas.2012-6139)

Klisch K, Contreras DA, Sun X, Brehm R, Bergmann M \& Alberio R 2011 The Sda/GM2-glycan is a carbohydrate marker of porcine primordial germ cells and of a subpopulation of spermatogonia in cattle, pigs, horses and Ilama. Reproduction 142 667-674. (doi:10.1530/REP-11-0007)

Kluin PM, Kramer MF \& de Rooij DG 1982 Spermatogenesis in the immature mouse proceeds faster than in the adult. International Journal of Andrology 5 282-294. (doi:10.1111/j.1365-2605.1982.tb00257.x)

Kurimoto K, Yamaji M, Seki Y \& Saitou M 2008 Specification of the germ cell lineage in mice: a process orchestrated by the PR-domain proteins, Blimp1 and Prdm14. Cell Cycle 7 3514-3518. (doi:10.4161/cc.7.22.6979)

Li H, Papadopoulos V, Vidic B, Dym M \& Culty M 1997 Regulation of rat testis gonocyte proliferation by platelet-derived growth factor and estradiol: identification of signaling mechanisms involved. Endocrinology 138 1289-1298.

Li Y, Zhang Y, Zhang X, Sun J \& Hao J 2014 BMP4/Smad signaling pathway induces the differentiation of mouse spermatogonial stem cells via upregulation of Sohlh2. Anatomical Record 297 749-757. (doi:10.1002/ ar.22891)

Liu Z, Miao D, Xia Q, Hermo L \& Wing SS 2007 Regulated expression of the ubiquitin protein ligase, E3(histone)/LASU1/Mule/ARF-BP1/HUWE1, during spermatogenesis. Developmental Dynamics 236 2889-2898. (doi:10.1002/dvdy.21302)

Livera G, Rouiller-Fabre V, Durand P \& Habert R 2000 Multiple effects of retinoids on the development of Sertoli, germ, and Leydig cells of fetal and neonatal rat testis in culture. Biology of Reproduction 62 1303-1314. (doi:10.1095/biolreprod62.5.1303)

Livera G, Rouiller-Fabre V, Pairault C, Levacher C \& Habert R 2002 Regulation and perturbation of testicular functions by vitamin $\mathrm{A}$. Reproduction 124 173-180. (doi:10.1530/rep.0.1240173)

Loveland KL, Hedger MP, Risbridger G, Herszfeld D \& de Kretser DM 1993 Identification of receptor tyrosine kinases in the rat testis. Molecular Reproduction and Development 36 440-447. (doi:10.1002/mrd. 1080360406)

Luo J, Megee S \& Dobrinski I 2009 Asymmetric distribution of UCH-L1 in spermatogonia is associated with maintenance and differentiation of spermatogonial stem cells. Journal of Cellular Physiology 220 460-468. (doi:10.1002/jcp.21789)

Manku G, Wing S \& Culty M 2012 Expression of the ubiquitin proteasome system in rat gonocytes and spermatogonia: role in gonocyte differentiation. Biology of Reproduction 87 44. (doi:10.1095/biolreprod.112. 099143)

Manku G, Wang Y, Merkbaoui V, Boisvert A, Ye X, Blonder J \& Culty M 2014 Role of Retinoic Acid and Platelet-Derived Growth Factor Receptor crosstalk in the regulation of neonatal gonocyte and embryonal carcinoma cell differentiation. Endocrinology 2014 en20141524. [Epub ahead of print]. PMID: 25380237.

Mark M, Jacobs H, Oulad-Abdelghani M, Dennefeld C, Féret B, Vernet N, Codreanu CA, Chambon P \& Ghyselinck NB 2008 STRA8-deficient spermatocytes initiate, but fail to complete, meiosis and undergo premature chromosome condensation. Journal of Cell Science $\mathbf{1 2 1}$ 3233-3242. (doi:10.1242/jcs.035071)

Marucci L, Pedone E, Di Vicino U, Sanuy-Escribano B, Isalan M \& Cosma MP $2014 \beta$-catenin fluctuates in mouse ESCs and is essential for Nanog-mediated reprogramming of somatic cells to pluripotency. Cell Reports 8 1686-1696. (doi:10.1016/j.celrep.2014.08.011)

Mather JP, Attie KM, Woodruff TK, Rice GC \& Phillips DM 1990 Activin stimulates spermatogonial proliferation in germ-Sertoli cell cocultures from immature rat testis. Endocrinology 127 3206-3214. (doi:10.1210/ endo-127-6-3206)

Matson CK, Murphy MW, Griswold MD, Yoshida S, Bardwell VJ \& Zarkower D 2010 The mammalian doublesex homolog DMRT1 is a transcriptional gatekeeper that controls the mitosis versus meiosis decision in male germ cells. Developmental Cell 19 612-624. (doi:10. 1016/j.devcel.2010.09.010)

Mclver SC, Stanger SJ, Santarelli DM, Roman SD, Nixon B \& McLaughlin EA 2012 A unique combination of male germ cell miRNAs coordinates gonocyte differentiation. PLoS ONE 7 e35553. (doi:10.1371/ journal.pone.0035553)

McKinnell C, Mitchell RT, Morris K, Anderson RA, Kelnar CJ, Hamish Wallace W \& Sharpe RM 2013 Perinatal germ cell development and differentiation in the male marmoset (Callithrix jacchus): similarities with the human and differences from the rat. Human Reproduction $\mathbf{2 8}$ 886-896. (doi:10.1093/humrep/des465)

McLean DJ, Friel PJ, Johnston DS \& Griswold MD 2003 Characterization of spermatogonial stem cell maturation and differentiation in neonatal mice. Biology of Reproduction 69 2085-2091. (doi:10.1095/biolreprod. 103.017020)

Meehan T, Schlatt S, O'Bryan MK, de Kretser DM \& Loveland KL 2000 Regulation of germ cell and Sertoli cell development by activin, follistatin, and FSH. Developmental Biology 220 225-237. (doi:10. 1006/dbio.2000.9625)

Mendis SH, Meachem SJ, Sarraj MA \& Loveland KL 2011 Activin A balances Sertoli and germ cell proliferation in the fetal mouse testis. Biology of Reproduction 84 379-391. (doi:10.1095/biolreprod.110.086231)

Meng X, Lindahl M, Hyvönen ME, Parvinen M \& de Rooij DG 2000 Regulation of cell fate decision of undifferentiated spermatogonia by GDNF. Science 287 1489-1493. (doi:10.1126/science.287.5457. 1489)

Merlet J, Racine C, Moreau E, Moreno SG \& Habert R 2007 Male fetal germ cells are targets for androgens that physiologically inhibit their proliferation. PNAS $\mathbf{1 0 4}$ 3615-3620. (doi:10.1073/pnas. 0611421104)

Mitchell RT, Cowan G, Morris KD, Anderson RA, Fraser HM, Mckenzie KJ, Wallace WH, Kelnar CJ, Saunders PT \& Sharpe RM 2008 Germ cell differentiation in the marmoset (Callithrix jacchus) during fetal and neonatal life closely parallels that in the human. Human Reproduction 23 2755-2765. (doi:10.1093/humrep/den295)

Mithraprabhu S, Mendis S, Meachem SJ, Tubino L, Matzuk MM, Brown CW \& Loveland KL 2010 Activin bioactivity affects germ cell differentiation in the postnatal mouse testis in vivo. Biology of Reproduction 82 980-990. (doi:10.1095/biolreprod.109.079855)

Mitranond V, Sobhon P, Tosukhowong P \& Chindaduangrat W 1979 Cytological changes in the testes of vitamin-A-deficient rats. I. Quantitation of germinal cells in the seminiferous tubules. Acta Anatomica 103 159-168. (doi:10.1159/000145007)

Morales C \& Griswold MD 1987 Retinol-induced stage synchronization in seminiferous tubules of the rat. Endocrinology 121 432-434. (doi:10. 1210/endo-121-1-432)

Mori C, Nakamura N, Dix DJ, Fujioka M, Nakagawa S, Shiota K \& Eddy EM 1997 Morphological analysis of germ cell apoptosis during postnatal testis development in normal and $\mathrm{Hsp} 70-2$ knockout mice. Developmental Dynamics 208 125-136. (doi:10.1002/(SICI)1097-0177 (199701)208:1 < 125::AID-AJA12 > 3.0.CO;2-5) 
Nagano MC \& Yeh JR 2013 The identity and fate decision control of spermatogonial stem cells: where is the point of no return? Current Topics in Developmental Biology 102 61-95.

Nagano M, Ryu BY, Brinster CJ, Avarbock MR \& Brinster RL 2003 Maintenance of mouse male germ line stem cells in vitro. Biology of Reproduction 68 2207-2214. (doi:10.1095/biolreprod.102.014050)

Nakagawa T, Nabeshima YI \& Yoshida S 2007 Functional identification of the actual and potential stem cell compartments in mouse spermatogenesis. Developmental Cell 12 195-206. (doi:10.1016/j.devcel.2007. 01.002)

Nakagawa T, Sharma M, Nabeshima Y, Braun RE \& Yoshida S 2010 Functional hierarchy and reversibility within the murine spermatogenic stem cell compartment. Science 328 62-67. (doi:10.1126/science. 1182868)

Nayernia K 2007 Stem cells derived from testis show promise for treating a wide variety of medical conditions. Cell Research 17 895-897. (doi:10.1038/cr.2007.96)

Niu Z, Goodyear SM, Rao S, Wu X, Tobias JW, Avarbock MR \& Brinster RL 2011 MicroRNA-21 regulates the self-renewal of mouse spermatogonial stem cells. PNAS 108 12740-12745. (doi:10.1073/pnas.1109987108)

Oatley JM \& Brinster RL 2012 The germline stem cell niche unit in mammalian testes. Physiological Reviews 92 577-595. (doi:10.1152/ physrev.00025.2011)

Oatley JM, Kaucher AV, Avarbock MR \& Brinster RL 2010 Regulation of mouse spermatogonial stem cell differentiation by STAT3 signaling. Biology of Reproduction 83 427-433. (doi:10.1095/biolreprod.109. 083352)

Orwig KE, Ryu BY, Avarbock MR \& Brinster RL 2002 Male germ-line stem cell potential is predicted by morphology of cells in neonatal rat testes. PNAS 99 11706-11711. (doi:10.1073/pnas.182412099)

O'Shaughnessy PJ \& Fowler PA 2014 Development of the human fetal testis. Annales d'Endocrinologie 75 48-53. (doi:10.1016/j.ando.2014.03.009)

Oulad-Abdelghani M, Bouillet P, Decimo D, Gansmuller A, Heyberger S, Dolle P, Bronner S, Lutz Y \& Chambon P 1996 Characterization of a premeiotic germ cell-specific cytoplasmic protein encoded by Stra8, a novel retinoic acid-responsive gene. Journal of Cell Biology 135 469-477. (doi:10.1083/jcb.135.2.469)

Palumbo C, van Roozendaal K, Gillis AJ, van Gurp RH, de Munnik H, Oosterhuis JW, van Zoelen EJ \& Looijenga LH 2002 Expression of the PDGF $\alpha$-receptor $1.5 \mathrm{~kb}$ transcript, OCT-4, and c-KIT in human normal and malignant tissues. Implications for the early diagnosis of testicular germ cell tumours and for our understanding of regulatory mechanisms. Journal of Pathology 196 467-477. (doi:10.1002/path.1064)

Pauls K, Schorle H, Jeske W, Brehm R, Steger K, Wernert N, Buttner R \& Zhou H 2006 Spatial expression of germ cell markers during maturation of human fetal male gonads: an immunohistochemical study. Human Reproduction 21 397-404. (doi:10.1093/humrep/dei325)

Payne CJ 2013 Cycling to and from a stem cell niche: the temporal and spatial odyssey of mitotic male germ cells. International Journal of Developmental Biology 57 169-177. (doi:10.1387/ijdb.130006cp)

Pinto ME, Botta LS, Taboga SR \& Góes RM 2010 Neonatal gonocyte differentiation in Mongolian gerbil Meriones unguiculatus involves asynchronous maturation of seminiferous cords and rapid formation of transitional cell stage. Anatomical Record 293 310-419. (doi:10.1002/ ar.21050)

Rajpert-De Meyts E 2006 Developmental model for the pathogenesis of testicular carcinoma in situ: genetic and environmental aspects. Human Reproduction Update 12 303-323. (doi:10.1093/humupd/dmk006)

Rajpert-De Meyts E \& Hoei-Hansen CE 2007 From gonocytes to testicular cancer: the role of impaired gonadal development. Annals of the New York Academy of Sciences 1120 168-180. (doi:10.1196/annals.1411.013)

Reik W, Dean W \& Walter J 2001 Epigenetic reprogramming in mammalian development. Science 293 1089-1093. (doi:10.1126/science.1063443)

de Rooij DG \& Russell LD 2000 All you wanted to know about spermatogonia but were afraid to ask. Journal of Andrology 21 776-798.

Rouillier-Fabre V, Levacher C, Pairault C, Racine C, Moreau E, Olaso R, Livera G, Migrenne S, Delbes G \& Habert R 2003 Development of the foetal and neonatal testis. Andrologia 35 79-83. (doi:10.1046/j.14390272.2003.00540.x)

Ryu BY, Orwig KE, Kubota H, Avarbock MR \& Brinster RL 2004 Phenotypic and functional characteristics of spermatogonial stem cells in rats. Developmental Biology 274 158-170. (doi:10.1016/j.ydbio.2004.07.004)
Sabatini DM 2006 mTOR and cancer: insights into a complex relationship. Nature Reviews. Cancer 6 729-734. (doi:10.1038/nrc1974)

Sada A, Hasegawa K, Pin PH \& Saga Y 2012 NANOS2 acts downstream of glial cell line-derived neurotrophic factor signaling to suppress differentiation of spermatogonial stem cells. Stem Cells 30 280-291. (doi:10.1002/stem.790)

Saitou M 2009 Germ cell specification in mice. Current Opinion in Genetics \& Development 19 386-395. (doi:10.1016/j.gde.2009.06. 003)

Schrans-Stassen BH, van de Kant HJ, de Rooij DG \& van Pelt AM 1999 Differential expression of kit in mouse undifferentiated and differentiating type A spermatogonia. Endocrinology 140 5894-5900. (doi:10.1210/ endo.140.12.7172)

Seki Y, Hayashi K, Itoh K, Mizugaki M, Saitou M \& Matsui Y 2005 Extensive and orderly reprogramming of genome-wide chromatin modifications associated with specification and early development of germ cells in mice. Developmental Biology 278 440-458. (doi:10.1016/j. ydbio.2004.11.025)

Sergeant KA, Bourgeois CF, Dalgliesh C, Venables JP, Stevenin J \& Elliott DJ 2007 Alternative RNA splicing complexes containing the scaffold attachment factor SAFB2. Journal of Cell Science 120 309-319. (doi:10.1242/jcs.03344)

Setchell BP, Hertel T, Soder O 2003 Postnatal testicular development, cellular organization and paracrine regulation. Endocrine Development 5 24-37. In The Developing Testis: Physiology and Pathophysiology. Ed O Söder. Basel: Karger.

Sharpe RM, Fraser HM, Brougham MF, McKinnell C, Morris KD, Kelnar CJ, Wallace WH \& Walker M 2003 Role of the neonatal period of pituitarytesticular activity in germ cell proliferation and differentiation in the primate testis. Human Reproduction 18 2110-2117. (doi:10.1093/ humrep/deg413)

Sheng XR, Posenau T, Gumulak-Smith JJ, Matunis E, Van Doren M \& Wawersik M 2009 Jak-STAT regulation of male germline stem cell establishment during Drosophila embryogenesis. Developmental Biology 334 335-344. (doi:10.1016/j.ydbio.2009.07.031)

Skakkebaek NE, Berthelsen JG, Giwercman A \& Muller J 1987 Carcinomain-situ of the testis: possible origin from gonocytes and precursor of all types of germ cell tumours except spermatocytoma. International Journal of Andrology 10 19-28. (doi:10.1111/j.1365-2605.1987. tb00161.x)

Skakkebaek NE, Rajpert-De Meyts E \& Main KM 2001 Testicular dysgenesis syndrome: an increasingly common developmental disorder with environmental aspects. Human Reproduction 16 972-978. (doi:10.1093/ humrep/16.5.972)

Snyder EM, Small C \& Griswold MD 2010 Retinoic acid availability drives the asynchronous initiation of spermatogonial differentiation in the mouse. Biology of Reproduction 83 783-790. (doi:10.1095/biolreprod. 110.085811)

Song HW \& Wilkinson MF 2014 Transcriptional control of spermatogonial maintenance and differentiation. Seminars in Cell \& Developmental Biology 30 14-26. (doi:10.1016/j.semcdb.2014.02.005)

Sonne SB, Almstrup K, Dalgaard M, Juncker AS, Edsgard D, Ruban L, Harrison NJ, Schwager C, Abdollahi A, Huber PE et al. 2009 Analysis of gene expression profiles of microdissected cell populations indicates that testicular carcinoma in situ is an arrested gonocyte. Cancer Research $695241-5250$.

Spradling A, Fuller MT, Braun RE \& Yoshida S 2011 Germline stem cells. Cold Spring Harbor Perspectives in Biology 3 a002642. (doi:10.1101/ cshperspect.a002642)

Steinberger E Steinberger A 1975 Spermatogenic function of the testis. In Handbook of Physiology, Section 7: Endocrinology, Volume 5, Male Reproductive System, pp 1-10. Eds RO Greep and DW Hamilton. Washington, DC: American Physiological Society.

Suzuki A \& Saga Y 2008 Nanos2 suppresses meiosis and promotes male germ cell differentiation. Genes and Development 22 430-435. (doi:10.1101/gad.1612708)

Suzuki H, Saga A, Yoshida S \& Saga Y 2009 The heterogeneity of spermatogonia is revealed by their topology and expression of marker proteins including the germ cell-specific proteins Nanos2 and Nanos3. Developmental Biology 336 222-231. (doi:10.1016/j.ydbio.2009. 10.002) 
Suzuki H, Ahn HW, Chu T, Bowden W, Gassei K, Orwig K \& Rajkovic A 2012 SOHLH1 and SOHLH2 coordinate spermatogonial differentiation. Developmental Biology 361 301-312. (doi:10.1016/j.ydbio.2011. 10.027)

Tedesco M, La Sala G, Barbagallo F, De Felici M \& Farini D 2009 STRA8 shuttles between nucleus and cytoplasm and displays transcriptional activity. Journal of Biological Chemistry 284 35781-35793. (doi:10. 1074/jbc.M109.056481)

Tegelenbosch RA \& de Rooij DG 1993 A quantitative study of spermatogonial multiplication and stem cell renewal in the $\mathrm{C} 3 \mathrm{H} / 101$ F1 hybrid mouse. Mutation Research 290 193-200. (doi:10.1016/00275107(93)90159-D)

Theodosiou M, Laudet V \& Schubert M 2010 From carrot to clinic: an overview of the retinoic acid signaling pathway. Cellular and Molecular Life Sciences 67 1423-1445. (doi:10.1007/s00018-0100268-z)

Thuillier R, Manku G, Wang Y \& Culty M 2009 Changes in MAPK pathway in neonatal and adult testis following fetal estrogen exposure and effects on rat testicular cells. Microscopy Research and Technique 72 773-786. (doi:10.1002/jemt.20756)

Thuillier R, Mazer M, Manku G, Boisvert A, Wang Y \& Culty M 2010 Interdependence of platelet-derived growth factor and estrogen-signaling pathways in inducing neonatal rat testicular gonocytes proliferation. Biology of Reproduction 82 825-836. (doi:10.1095/biolreprod.109. 081729)

Tong MH, Mitchell DA, McGowan SD, Evanoff R \& Griswold MD 2012 Two miRNA clusters, Mir-17-92 (Mirc1) and Mir-106b-25 (Mirc3), are involved in the regulation of spermatogonial differentiation in mice. Biology of Reproduction 86 72. (doi:10.1095/biolreprod.111.096313)

Trasler JM 2009 Epigenetics in spermatogenesis. Molecular and Cellular Endocrinology 306 33-36. (doi:10.1016/j.mce.2008.12.018)

Travers A, Arkoun B, Safsaf A, Milazzo JP, Absyte A, Bironneau A, Perdrix A, Sibert L, Macé B, Cauliez B et al. 2013 Effects of vitamin A on in vitro maturation of pre-pubertal mouse spermatogonial stem cells. PLoS ONE 8 e82819. (doi:10.1371/journal.pone.0082819)

Valli H, Phillips BT, Shetty G, Byrne JA, Clark AT, Meistrich ML \& Orwig KE 2014 Germline stem cells: toward the regeneration of spermatogenesis. Fertility and Sterility 101 3-13. (doi:10.1016/j.fertnstert.2013.10.052)

Van Pelt AM \& de Rooij DG 1990 Synchronization of the seminiferous epithelium after vitamin A replacement in vitamin A-deficient mice. Biology of Reproduction 43 363-367. (doi:10.1095/biolreprod43.3.363)

Van Pelt AM \& de Rooij DG 1991 Retinoic acid is able to reinitiate spermatogenesis in vitamin A deficient rats and high replicate doses support the full development of spermatogenic cells. Endocrinology 128 697-704. (doi:10.1210/endo-128-2-697)

Vernet N, Dennefeld C, Guillou F, Chambon P, Ghyselinck NB \& Mark M 2006a Prepubertal testis development relies on retinoic acid but not retinoid receptors in Sertoli cells. EMBO Journal 25 5816-5825. (doi:10. 1038/sj.emboj.7601447)

Vernet N, Dennefeld C, Rochette-Egly C, Oulad-Abdelghani $M$, Chambon P, Ghyselinck NB \& Mark M 2006b Retinoic acid metabolism and signaling pathways in the adult and developing mouse testis. Endocrinology 147 96-110. (doi:10.1210/en.2005-0953)

Wang Y \& Culty M 2007 Identification and distribution of a novel plateletderived growth factor receptor $\beta$ variant: effect of retinoic acid and involvement in cell differentiation. Endocrinology 148 2233-2250. (doi:10.1210/en.2006-1206)

Weber S, Eckert D, Nettersheim D, Gillis AJ, Schäfer S, Kuckenberg P, Ehlermann J, Werling U, Biermann K, Looijenga LH et al. 2010 Critical function of AP- $2 \gamma /$ TCFAP2C in mouse embryonic germ cell maintenance. Biology of Reproduction 82 214-223. (doi:10.1095/biolreprod. 109.078717)

Wu Z, Luby-Phelps K, Bugde A, Molyneux LA, Denard B, Li WH, Süel GM \& Garbers DL 2009 Capacity for stochastic self-renewal and differentiation in mammalian spermatogonial stem cells. Journal of Cell Biology 187 513-524. (doi:10.1083/jcb.200907047)

Yeh JR, Zhang X \& Nagano MC 2011 Wnt5a is a cell-extrinsic factor that supports self-renewal of mouse spermatogonial stem cells. Journal of Cell Science 124 2357-2366. (doi:10.1242/jcs.080903)

Yeh JR, Zhang X \& Nagano MC 2012 Indirect effects of Wnt3a/ $\beta$-catenin signalling support mouse spermatogonial stem cells in vitro. PLOS ONE 7 e40002. (doi:10.1371/journal.pone.0040002)

Yoshida S, Sukeno M, Nakagawa T, Ohbo K, Nagamatsu G, Suda T \& Nabeshima Y 2006 The first round of mouse spermatogenesis is a distinctive program that lacks the self-renewing spermatogonia stage. Development 133 1495-1505. (doi:10.1242/dev.02316)

Yu M, Mu H, Niu Z, Chu Z, Zhu H \& Hua J 2014 miR-34c enhances mouse spermatogonial stem cells differentiation by targeting Nanos2. Journal of Cellular Biochemistry 115 232-242. (doi:10.1002/jcb.24655)

Zhang L, Tang J, Haines CJ, Feng H, Lai L, Teng X \& Han Y 2013a c-kit expression profile and regulatory factors during spermatogonial stem cell differentiation. BMC Developmental Biology 13 38. (doi:10.1186/1471213X-13-38)

Zhang Z, Gong Y, Guo Y, Hai Y, Yang H, Yang S, Liu Y, Ma M, Liu L, Li Z et al. $2013 \mathrm{~b}$ Direct transdifferentiation of spermatogonial stem cells to morphological, phenotypic and functional hepatocyte-like cells via the ERK $1 / 2$ and Smad2/3 signaling pathways and the inactivation of cyclin $\mathrm{A}$, cyclin B and cyclin E. Cell Communication and Signaling 11 67. (doi:10. 1186/1478-811X-11-67)

Zhao GQ \& Garbers DL 2002 Male germ cell specification and differentiation. Developmental Cell 2 537-547. (doi:10.1016/S15345807(02)00173-9)

Zheng B, Zhou Q, Guo Y, Shao B, Zhou T, Wang L, Zhou Z, Sha J, Guo X \& Huang X 2014 Establishment of a proteomic profile associated with gonocyte and spermatogonial stem cell maturation and differentiation in neonatal mice. Proteomics 14 274-285. (doi:10.1002/pmic.201300395)

Zhou B \& Hutson JM 1995 Human chorionic gonadotropin (hCG) fails to stimulate gonocyte differentiation in newborn mouse testes in organ culture. Journal of Urology 153 501-505. (doi:10.1097/00005392199502000-00071)

Zhou Q, Nie R, Li Y, Zhou Q, Nie R, Li Y, Friel P, Mitchell D, Hess RA, Small C et al. 2008a Expression of stimulated by retinoic acid gene 8 (Stra8) in spermatogenic cells induced by retinoic acid: an in vivo study in vitamin A-sufficient postnatal murine testes. Biology of Reproduction 79 35-42. (doi:10.1095/biolreprod.107.066795)

Zhou Q, Li Y, Nie R, Friel P, Mitchell D, Evanoff RM, Pouchnik D, Banasik B, McCarrey JR, Small C et al. 2008b Expression of stimulated by retinoic acid gene 8 (Stra8) and maturation of murine gonocytes and spermatogonia induced by retinoic acid in vitro. Biology of Reproduction 78 537-545. (doi:10.1095/biolreprod.107.064337)

Received 20 August 2014

First decision 30 September 2014

Revised manuscript received 13 November 2014

Accepted 20 November 2014 